\title{
Screening of Serum Protein Markers for Avascular Osteonecrosis of Femoral Head Differentially Expressed after Treatment with Yuanshi Shengmai Chenggu Tablets
}

\author{
Peng Deng, ${ }^{1}$ Jianchun Zeng, ${ }^{2}$ Jie Li, ${ }^{2}$ Wenjun Feng, ${ }^{2}$ Jinlun Chen, ${ }^{2}$ and Yirong Zeng $\mathbb{D}^{2}$ \\ ${ }^{1}$ The First Clinical Medical College, Guangzhou University of Chinese Medicine, 16 Jichang Road, Baiyun District, \\ Guangzhou, Guangdong Province 510405, China \\ ${ }^{2}$ The Third Department of Orthopedics, The First Affiliated Hospital of Guangzhou University of Chinese Medicine, \\ Guangzhou, Guangdong Province 510405, China
}

Correspondence should be addressed to Yirong Zeng; zengyirong2016@yeah.net

Received 28 August 2017; Revised 4 January 2018; Accepted 22 January 2018; Published 20 March 2018

Academic Editor: Yu-Chang Tyan

Copyright ( $(2018$ Peng Deng et al. This is an open access article distributed under the Creative Commons Attribution License, which permits unrestricted use, distribution, and reproduction in any medium, provided the original work is properly cited.

\begin{abstract}
Avascular necrosis of the femoral head (ANFH) is an a frequently occurring orthopaedic disease with high morbidity. Traditional Chinese Medicine (TCM) Yuanshi Shengmai Chenggu Tablet is a valid prescription for treating steroid-induced femoral head necrosis. However, there are rare investigations about the serum protein marker expression after the acting of drugs on hormone and TCM. In the present study, we aimed to systematically discover and validate the serum biomarkers expression difference in patients with steroid-induced avascular necrosis of femoral head (SANFH) after taking Yuanshi Shengmai Chenggu Tablets (SANFH-TCM), so as to reveal the action mechanism of TCM from the molecular level by using isobaric tags for relative and absolute quantification (iTRAQ) with multiple reaction monitoring quantification. Significant differences in fibrinogen alpha, fibrinogen beta, fibrinogen gamma, fibronectin, C-reactive protein, apolipoprotein A, apolipoprotein D, and apolipoprotein E were found among SANFH, SANFH-TCM, and healthy controls. Therefore, our study proposes potential biomarkers for SANFH diagnosis and for the prognosis of femoral head necrosis after Traditional Chinese Medicine treatment.
\end{abstract}

\section{Introduction}

Avascular necrosis of the femoral head (ANFH) is a clinical common orthopaedic disease [1-3] with very high morbidity. It is difficult to cure and is one of the major medical problems that have not yet been overcome $[4,5]$. Primary osteonecrosis of the femoral head is due to gene or gene mutation of patients. Secondary osteonecrosis of the femoral head could divide into traumatic and nontraumatic osteonecrosis of femoral head [6-8], in which traumatic osteonecrosis of the femoral head is the avascular necrosis of osteocyte caused by interruption of blood flow in the blood vessels in femoral head, which was due to trauma $[9,10]$. Its etiology is still unclear. It was demonstrated that long-term and large dosage usage of hormone and drinking are two important factors that cause ANFN $[4,11]$. In recent years, with the wide use of corticosteroids clinically, the cases with ANFN have also increased greatly $[12,13]$. However, the pathogenesis of steroid-induced ANFN is still unknown. For developing new methods to prevent and treat ANFN, study on the pathogenesis of steroid-induced ANFN is particularly urgent $[12,14,15]$.

Recent reports have shown that the occurrence of ANFN could be greatly decreased by an early intervention on highrisk crowds of ANFN who use hormones such as steroid and alcohol [16]. However, the composition of the serum is very complex [17]. It contains high-abundance proteins like albumin and immunoglobulins (mainly IgG), as well as low abundance proteins that are secreted by tissue or cells $[18,19]$. Some of them are key proteins involved in signal transduction and regulation [20]. Tan et al. [21] adopted two-dimensional electrophoresis technology and separated 7 differentially expressed proteins between patients with primary femoral head necrosis and normal subjects from 10 pairs serum samples. They found that four important proteins including tissuetype plasminogen activator ( $\mathrm{t}-\mathrm{PA})$, plasminogen activator 
inhibitor type 1 (PAI-1), Crosslaps, and anti-p53 antibody were significantly changed and that all of them can be used as the diagnosis serum markers of nontraumatic femoral head necrosis. Although the pathogenesis of ANFN is still unclear and the relevance of this finding with the further clinical application was not reported, analysis of the differentially expressed proteins in the serum could provide useful information.

Traditional Chinese Medicine (TCM) Yuanshi Shengmai Chenggu Tablet is valid and specialty drug for steroidinduced ANFN treatment. Yuanshi Shengmai Chenggu Tablet has obtained the certificate of new medicine in China and has been applied in clinical [22]. Its active ingredients are mainly flavonoids such as vitexin. By clinical studies, it was demonstrated the application of Yuanshi Shengmai Chenggu Tablet can significantly relieve the patients' pain and accelerate the absorption of dead bone and formation of new bone, showing a relatively strong osteogenetic activity [22].

Liu et al. [23] extracted proteins in bone tissue from the femur and humerus bone in rat osteonecrosis model with or without Yuanshi Shengmai Chenggu Tablet TCM treatment and performed proteomics research. They reported that anticoagulating proteins heavy chain II B, phospholipid hydroperoxide glutathione peroxidase, and ubiquitin enzymes E2 (MW: $17 \mathrm{kD}$ ) are closely associated with steroidinduced bone necrosis, as well as the therapeutic efficacy of TCM.

In this study we aimed to investigate the differentially expressed protein in serum between steroid-induced ANFN patients with or without TCM treatment (Yuanshi Shengmai Chenggu Tablets). For this purpose, the proteomics method isobaric tags for relative and absolute quantification (iTRAQ) with multiple reaction monitoring (MRM) quantification was adopted in this study, so as to reveal the molecular mechanism of TCM treated the SANFN in the molecular level.

\section{Material and Methods}

2.1. Participants. Patients diagnosed as ANFN in the First Affiliated Hospital of Traditional Chinese Medicine University of Guangzhou from February 2014 to February 2015 were included. The ANFN diagnosis was established by referring to standard of adult femoral head necrosis diagnosis expert consensus (2012 edition) and the diagnosis and treatment of avascular necrosis of the expert advice of diagnostic criteria. Patients in active period of ANFN, alcoholics who are simultaneously treated by long-term high dose of glucocorticoids (taken steroid $>10 \mathrm{mg} / \mathrm{d}$ longer than 3 years), or patients with combining chronic disease which needs prolonged treatment were excluded in present study. All participants gave written informed consent before being enrolled in the study (AE2013012011).

2.2. Specimens and Groups. Patients with ANFN who have used long-term and high-dosage of steroid (SANFN) were further treated with TCM Yuanshi Shengmai Chenggu Tablet
(6 tablets each time, 3 times per day, total 3 months; prepared by the First Affiliated Hospital of Guangzhou University of Traditional Chinese Medicine, Guangzhou, China). Serum samples $(n=5)$ from patients with or without TCM were prospectively collected after obtaining written informed consent. The study protocol was approved by the Ethics Committee of the First Affiliated Hospital of Guangzhou University of Traditional Chinese Medicine. Five healthy subjects were collected during the same period who were sex- and age-matched. Thus, the verification population was divided into 3 groups: steroid-induced avascular necrosis of femoral head (SANFH), SANFH-TCM treatment, and healthy controls.

All serum samples were centrifuged at $1250 \mathrm{~g}$ for $5 \mathrm{~min}$ and then $13500 \mathrm{~g}$ for $15 \mathrm{~min}$ at $4^{\circ} \mathrm{C}$ within $1 \mathrm{~h}$ of collection. All samples were then stored at $-80^{\circ} \mathrm{C}$ until use.

2.3. iTRAQ Analysis of Serum Samples. iTRAQ labeling and mass spectrometry analysis were performed as previously described [24]. Then, six iTRAQ labeled sample polls were generated (steroid-induced avascular necrosis of femoral head, SANFH-TCM treatment, and health controls, each for two subgroups). Briefly, high-abundance serum proteins such as albumin, IgG, and haptoglobin were removed by using the Human 14 Multiple Affinity Removal System (Agilent Technologies, Santa Clara, CA, USA). Then, $50 \mu \mathrm{g}$ protein of each sample was concentrated and desalted, followed by digestion using trypsin before iTRAQ labeling. Six groups were labeled, including steroid-induced avascular necrosis of femoral head, iTRAQ reagent 113, 116; SANFH-TCM treatment 114, 117; and health controls 115, 118. The six sample groups were mixed, desalted, and dried.

The ITRAQ labeled peptides were separated by Strong Cation Exchange (SCX) chromatography (Bonna-Agela Technologies, Tianjin, China). SCX was carried out on a Polysulfoethyl $4.6 \times 100 \mathrm{~mm}$ column $(5 \mu \mathrm{m}, 200 \AA$, PolyLC Inc., Maryland, USA). The peptides were eluted at the 45 min gradient from $100 \%$ buffer $\mathrm{A}\left(10 \mathrm{mM} \mathrm{KH}_{2} \mathrm{PO}_{4} \mathrm{pH}\right.$ 3.0, $25 \%$ acetonitrile) to $45 \%$ buffer $\mathrm{B}\left(10 \mathrm{mM} \mathrm{KH}_{2} \mathrm{PO}_{4}\right.$ pH 3.0, $500 \mathrm{mM} \mathrm{KCl}, 25 \%$ acetonitrile) at the flow rate of $800 \mu \mathrm{L} / \mathrm{min}$ on Agilent $1210 \mathrm{LC}$ system. All the fractions were analyzed by MALDI-TOF/TOF 5800 mass spectrometer (AB SCIEX, California, USA). Protein quantification and identification were performed with the Proteome Discoverer (version 1.3, thermos). The default bias correction was used and all quantitative variables were analyzed by the Proteome Discoverer 1.3. Peptide abundances were calculated based on the areas of the monoisotopic peaks. Protein ratios were the average ratios of all quantified peptides. Proteins with quantification $P$ value $<0.05$ in at least two pairs $(113: 114$, $113: 115,114: 115 ; 116: 117,116: 118,117: 118)$ and with the ratio $>1.2$ (the average ratio of two repeat experiments) or ratio $<0.83$ were considered as differentially expressed proteins, using a cutoff of 2 times standard deviation [25].

2.4. Bioinformatics Analysis. Biomarker candidates were then prioritized using scoring a system based on ITRAQ values from Proteome Discoverer analysis. The cellular component, 
molecular function, and biological process were analyzed through Gene Ontology (GO) database. The Kyoto Encyclopedia of Genes and Genomes (KEGG) pathway mapping was performed by KEGG Mapper (http://www.genome .jp/kegg/mapper.html), and the enrichment analysis was performed by Blast2GO PRO software (https://www.blast2go .com/, version 2.8).

2.5. Validation of Differential Expressed Protein by Multiple Reaction Monitoring (MRM) Quantification. To validate the expression of biomarker candidates, MRM quantifications were performed as previously described [26]. Briefly, $30 \mu \mathrm{g}$ protein of each sample was digested using trypsin before being desalted. Then, desalted peptide mixtures were loaded onto an Acclaim PePmap C18-reversed phase column (100 Å, Thermo Scientific, Massachusetts, USA) and separated with reversed phase C18 column (300 Á, BonnaAgela Technologies) mounted on a Dionex ultimate 3000 nano-LC system. Peptides were eluted using a gradient of $5-80 \%(\mathrm{v} / \mathrm{v})$ acetonitrile in $0.1 \%$ formic acid over $45 \mathrm{~min}$ at a flow rate of $300 \mathrm{~nL} / \mathrm{min}$ combined with a Q Exactive mass spectrometer (Thermo Scientific, Massachusetts, USA), and then the eluates were directly entered in Q Exactive MS (Thermo Scientific, Massachusetts, USA), setting in positive ion mode and data-dependent manner with full MS scan within $350-2000 \mathrm{~m} / z$, full scan resolution at 70000 , MS/MS scan resolution at 17500 , and MS/MS scan with minimum signal threshold $1 E+5$, isolation width at $2 \mathrm{Da}$. To evaluate the performance of this mass spectrometry on the iTRAQ labeled samples, two MS/MS acquisition modes and higher collision energy dissociation (HCD) were employed. And to optimize the MS/MS acquisition efficiency of HCD, normalized collision energy (NCE) was systemically examined, stepped 20\%. Each MS/MS spectrum was searched against a mascot database (Uniprot_2015_human database, 20194 protein entries) and a decoy database for FDR analysis (programmed in the software). The search parameters were as follows: sample type, iTRAQ 8-plex (Peptide Labeled); cysteine modification by methyl methane-thiosulfonate; digestion, trypsin enzyme; proteins with, at least, two peptides with a high confidence score $(>95 \%)$ and a low FDR (estimated local FDR of 5\%) were considered positively identified.

2.6. Statistical Analysis. All studies to identify biomarkers by iTRAQ/MRM LC-MS/MS were performed on three separate occasions. Statistical analysis was performed using $\mathrm{R}$ (version 3.4.2, Bell Laboratories, USA). Analysis of variance (ANOVA) was performed for groups comparison. A $P$ value $<0.05$ was considered as statistical significantly.

\section{Results}

3.1. Populations. A total of 26 patients were included in the present study. Demographic characteristics of present population were summarized in Table 1 . All of them were diagnosed as Association Research Circulation Osseous (ARCO) II stage SONFH, and the time windows of being illness were
TABLE 1: Demographic characteristics.

\begin{tabular}{lc}
\hline In Total $n$ & 26 \\
\hline Male, $n(\%)$ & $11(42.3)$ \\
Age, yr, mean \pm SD & $39.5 \pm 5.3$ \\
History of SONFH, months, median (min, max) & $23.1(6,34)$ \\
Primary disease, $n(\%)$ & \\
Systemic lupus erythematosus & $13(50.0)$ \\
Anaphylactoid purpura & $5(19.2)$ \\
Eczema & $4(15.4)$ \\
Psoriasis & $2(7.7)$ \\
Thrombocytopenic purpura & $1(3.8)$ \\
Fever of unknown origin & $1(3.8)$ \\
\hline
\end{tabular}

from 6 to 34 months. The mean age was 39.5 years old and $11(42.3 \%)$ of them were males, suggesting that the patients SONFH were younger. Primary cause of $50 \%$ of patients was systemic lupus erythematosus, indicating a high risk of long-term high dose of steroid in systemic lupus erythematosus.

\subsection{Protein Identification and Differentially Abundant} Proteins. Serum proteins of steroid-induced ANSF (SANFH) patients, SANFH-TCM treatment patients, and health subjects were screened using iTRAQ. The experiment was repeated twice and detected 399 proteins. Among them, 61 proteins were differentially expressed between SANFH and healthy controls (Table 2), including 35 significantly upregulated proteins $(>1.21$-fold, $P<0.05)$ and 26 significantly downregulated proteins $(<0.83$-fold, $P<0.05)$. The top four upregulated proteins in SANFH compared to healthy controls were serum amyloid A-2 (SAA2), Ig lambda, sodium/potassium-transporting ATPase subunit alpha-3 (ATP1A3), and calcium-binding mitochondrial carrier protein Aralarl (SLC25A12) with fold change values of 4.57, 2.64, 2.07, and 1.95. The top four downregulated proteins were properdin, keratin type I cytoskeletal 9 (KRT9), apolipoprotein (a) (LPA), and tropomyosin alpha-4 (TPM4) with fold change values of $-1.77,-1.57,-1.65$, and -1.61 , respectively.

A total of 74 proteins were differentially expressed between SANFH-TCM and healthy controls (Table 3), including 45 significantly upregulated proteins $(>1.21$-fold, $P<$ $0.05)$, and 29 significantly downregulated proteins $(<0.83$ fold, $P<0.05$ ). The top four upregulated proteins in SANFHTCM compared to healthy controls were ATP-binding cassette subfamily B member 9 (ABCB9), fibrinogen alpha, fibrinogen gamma, and fibrinogen beta with fold change values of 17.47, 13.05, 12.67, and 12.11. The top four downregulated proteins were C-reactive protein (CRP), Tubulin alpha-1A (TUBA1A), fibronectin, and LPA with fold change values of $-1.73,-1.73,-1.52$, and -1.48 , respectively.

In addition, a total of 81 proteins were differentially expressed between SANFH-TCM and SANFH (Table 4), including significantly 44 upregulated proteins $(>1.21$-fold, $P<0.05)$ and 37 significantly downregulated proteins 
TABLE 2: Differentially expressed protein between SANFH and healthy controls.

\begin{tabular}{|c|c|c|c|}
\hline Accession & Description & $P$ value & Ratio (mean) \\
\hline \multicolumn{4}{|c|}{ Upregulated protein } \\
\hline P0DJI9 & Serum amyloid A-2 protein & 0.0000233 & 4.57402273 \\
\hline P01714 & Ig lambda chain V-III region $\mathrm{SH}$ & 0.000116405 & 2.64233333 \\
\hline P13637 & Sodium/potassium-transporting ATPase subunit alpha-3 & 0.010160416 & 2.06683333 \\
\hline O75746 & Calcium-binding mitochondrial carrier protein Aralarl & 0.008612823 & 1.95325 \\
\hline P01613 & Ig kappa chain V-I region $\mathrm{Ni}$ & 0.005619256 & 1.94854167 \\
\hline P01743 & Ig heavy chain V-I region HG3 & 0.00017147 & 1.93190909 \\
\hline P01742 & Ig heavy chain V-I region EU & $1.61 E-18$ & 1.8255 \\
\hline P0DJI8 & Serum amyloid A-1 protein & 0.000000019 & 1.72607353 \\
\hline P01857 & Ig gamma-1 chain $\mathrm{C}$ region & $2.12 E-208$ & 1.71611466 \\
\hline P01861 & Ig gamma- 4 chain $\mathrm{C}$ region & 0.00000135 & 1.66788889 \\
\hline P06889 & Ig lambda chain V-IV region MOL & 0.0000383 & 1.59966667 \\
\hline $\mathrm{P} 01860$ & Ig gamma- 3 chain $\mathrm{C}$ region & $6.59 E-46$ & 1.59404098 \\
\hline P02741 & C-reactive protein & $6.38 E-146$ & 1.58455808 \\
\hline Q8NBJ4 & Golgi membrane protein 1 & 0.000564362 & 1.4622 \\
\hline P0C0L4 & Complement C4-A & $1.33 E-10$ & 1.45864286 \\
\hline P12235 & ADP/ATP translocase 1 & 0.016291795 & 1.4491 \\
\hline P06576 & ATP synthase subunit beta, mitochondrial & 0.002154497 & 1.43466667 \\
\hline P13645 & Keratin, type I cytoskeletal 10 & $4.63 E-13$ & 1.41348333 \\
\hline P04433 & Ig kappa chain V-III region VG (Fragment) & 0.000000732 & 1.412 \\
\hline Q08380 & Galectin-3-binding protein & $3.33 E-45$ & 1.38927444 \\
\hline Q14624 & Inter-alpha-trypsin inhibitor heavy chain $\mathrm{H} 4$ & $6.37 E-87$ & 1.37619099 \\
\hline P22692 & Insulin-like growth factor-binding protein 4 & 0.025918263 & 1.362 \\
\hline P01620 & Ig kappa chain V-III region SIE & $8.22 E-09$ & 1.3591875 \\
\hline P02452 & Collagen alpha-1(I) chain & $1.95 E-09$ & 1.3503 \\
\hline O75636 & Ficolin-3 & $2.26 E-53$ & 1.341312 \\
\hline P01717 & Ig lambda chain V-IV region Hil & 0.003213417 & 1.3341 \\
\hline P14625 & Endoplasmin & 0.00000523 & 1.3105 \\
\hline P01621 & Ig kappa chain V-III region NG9 (Fragment) & 0.000190716 & 1.2999 \\
\hline P51884 & Lumican & 0.002279512 & 1.29618421 \\
\hline P02747 & Complement Clq subcomponent subunit C & $1.85 E-11$ & 1.290775 \\
\hline P25705 & ATP synthase subunit alpha, mitochondrial & 0.00000765 & 1.28091667 \\
\hline P22792 & Carboxypeptidase $\mathrm{N}$ subunit 2 & $7.1 E-09$ & 1.27185227 \\
\hline P09543 & $2^{\prime}, 3^{\prime}$-Cyclic-nucleotide $3^{\prime}$-phosphodiesterase & 0.034218978 & 1.2625 \\
\hline P18428 & Lipopolysaccharide-binding protein & $2.71 E-47$ & 1.25414706 \\
\hline P01009 & Alpha-1-antitrypsin & $6.68 E-34$ & 1.21782482 \\
\hline \multicolumn{4}{|c|}{ Downregulated protein } \\
\hline P01781 & Ig heavy chain V-III region GAL & 0.00000597 & 0.82966667 \\
\hline O43852 & Calumenin & 0.000374747 & 0.82916667 \\
\hline Q9UK55 & Protein Z-dependent protease inhibitor & $2.62 E-11$ & 0.82908108 \\
\hline O43866 & CD5 antigen-like & $1.19 E-23$ & 0.82744578 \\
\hline Q04756 & Hepatocyte growth factor activator & 0.000530289 & 0.821 \\
\hline P63104 & 14-3-3 protein zeta/delta & 0.009022339 & 0.8194 \\
\hline Q68CQ4 & Digestive organ expansion factor homolog & 0.000458581 & 0.81775 \\
\hline P68366 & Tubulin alpha-4A chain & 0.003314178 & 0.8143 \\
\hline P04211 & Ig lambda chain $\mathrm{V}$ region $4 \mathrm{~A}$ & 0.021633191 & 0.812 \\
\hline Q6Q788 & Apolipoprotein A-V & 0.000000051 & 0.8107381 \\
\hline P59665 & Neutrophil defensin 1 & 0.011081692 & 0.7993 \\
\hline P05164 & Myeloperoxidase & 0.001604817 & 0.7984 \\
\hline P02649 & Apolipoprotein E & $5.01 E-267$ & 0.7911827 \\
\hline P04070 & Vitamin K-dependent protein C & $1.41 E-22$ & 0.78128922 \\
\hline Q13103 & Secreted phosphoprotein 24 & $9.56 E-09$ & 0.76858333 \\
\hline
\end{tabular}


TABLE 2: Continued.

\begin{tabular}{lccc}
\hline Accession & Description & P value & Ratio (mean) \\
\hline P02749 & beta-2-Glycoprotein 1 & 0.015081278 & 0.7567 \\
P01591 & Immunoglobulin J chain & $2.38 E-17$ & 0.75358772 \\
P36980 & Complement factor H-related protein 2 & 0.75325 \\
P04220 & Ig mu heavy chain disease protein & 0.000968476 & 0.74433333 \\
P01871 & Ig mu chain C region & 0.047631742 & 0.72098342 \\
Q71U36 & Tubulin alpha-1A chain & $2.52 E-147$ & 0.716 \\
P62158 & Calmodulin & 0.005388449 & 0.63166667 \\
P67936 & Tropomyosin alpha-4 chain & 0.002744078 & 0.62 \\
P08519 & Apolipoprotein(a) & 0.002042575 & 0.606 \\
P35527 & Keratin, type I cytoskeletal 9 & $1.36 E-09$ & 0.57923077 \\
P27918 & Properdin & $1.13 E-09$ & 0.57908333 \\
\hline
\end{tabular}

( $<0.83$-fold, $P<0.05$ ). The top four upregulated proteins in SANFH-TCM compared to SANFH were ABCB9, IQ, and AAA domain-containing protein 1 (IQCA1), fibrinogen alpha, and fibrinogen beta, which showed the fold change values of $21.82,13.86,13.66$, and 13.64, respectively. The top four downregulated proteins were serum amyloid A2 (SAA2), Ig lambda, CRP, and collagen alpha-1 with fold change values of $-2.36,-2.26,-2.24$, and -2.04 , respectively.

3.3. Biomarkers Prediction and Validation. MRM was performed to verify the results obtained from iTRAQ proteomics (Figure 1). The upregulation of fibrinogen alpha, fibrinogen beta, and fibrinogen gamma and apolipoprotein A (LPA) and apolipoprotein D (LPD) in SANFH-TCM versus healthy controls and SANFH-TCM versus SANFH was confirmed by MRM, respectively $(P<0.05)$. Meanwhile, MRM also verified the decreased expression of fibronectin and CRP in SANFH-TCM versus healthy controls and SANFH-TCM versus SANFH identified by iTRAQ, respectively $(P<0.05)$ (Table 5). In SANFH versus healthy controls, CRP and LPA were confirmed to upregulate, and LPD and apolipoprotein E (LPE) were confirmed to downregulate. Using MRM, fibrinogen alpha, fibrinogen beta, and fibrinogen gamma were significantly increased in SANFH compared with healthy controls. However, iTRAQ did not detect significant changes in the expression of fibrinogen alpha, fibrinogen beta, and fibrinogen gamma between SANFH and healthy controls. Although some difference existed between iTRAQ and MRM, all these data added confidence to the results obtained from iTRAQ.

3.4. Go Analysis of Differentially Expressed Proteins. The differentially expressed proteins (SANFH versus healthy controls, SANFH-TCM versus healthy controls, and SANFHTCM versus SANFH) were classified by Gene Ontology (GO) based on their cellular component, molecular function, and biological process.

For SANFH versus healthy controls (Figure 2), the top five significantly enriched GO terms concerning biological process were mainly associated with purine ribonucleotide biosynthetic process, nucleoside phosphate biosynthetic process, negative regulation of endothelial cell proliferation, mitochondrial transport and immune response-regulating signaling pathway, and cellular component, in which the top listed five GO terms were proton-transporting two-sector ATPase complex, catalytic domain, proton-transporting twosector ATPase complex, proton-transporting ATP synthase complex, pigment granule, and organelle inner membrane. With respect to molecular function, transmembrane transporter activity, substrate-specific transmembrane transporter activity, primary active transmembrane transporter activity, p-p-bond-hydrolysis-driven transmembrane transporter activity, and monovalent inorganic cation transmembrane transporter activity were the top five GO terms.

For SANFH-TCM versus healthy controls (Figure 3), transport, response to organic substance, response to chemical, response to calcium ion, and regulation of triglyceride metabolic process were the top five GO terms concerning biological process; vesicle lumen, site of polarized growth, secretory granule lumen, secretory granule, and platelet alpha granule lumen were the top five GO terms concerning cellular component; and sulfur compound binding, small molecule binding, serine-type endopeptidase inhibitor activity, quaternary ammonium group binding, and peptidase regulator activity were the top five GO terms concerning molecular function.

For SANFH-TCM versus SANFH (Figure 4), most enriched GO terms were response to metal ion, response to inorganic substance, response to calcium ion, regulation of lipoprotein oxidation, and protein polymerization in biological process, site of polarized growth, secretory granule lumen, secretory granule, ribosome, and platelet alpha granule in cellular component, and sulfur compound binding, serinetype endopeptidase inhibitor activity, scavenger receptor activity, ribonuclease activity, and ribonuclease A activity in molecular function.

\subsection{Pathway Enrichment Analysis of Differentially Expressed} Proteins. The differentially expressed proteins (SANFH versus healthy controls, SANFH-TCM versus healthy controls, and SANFH-TCM versus SANFH) were mapped to the 
TABLE 3: Differentially expressed protein between SANFH-TCM and healthy controls.

\begin{tabular}{|c|c|c|c|}
\hline Accession & Description & $P$ value & Ratio (mean) \\
\hline \multicolumn{4}{|c|}{ Upregulated protein } \\
\hline Q9NP78 & ATP-binding cassette subfamily B member 9 & $8.47 E-09$ & 17.47338 \\
\hline P02671 & Fibrinogen alpha chain & 0 & 13.049 \\
\hline P02679 & Fibrinogen gamma chain & 0 & 12.66544 \\
\hline P02675 & Fibrinogen beta chain & 0 & 12.11164 \\
\hline Q86XH1 & IQ and AAA domain-containing protein 1 & 0.000199 & 8.9745 \\
\hline P01019 & Angiotensinogen & $9.49 E-09$ & 2.256 \\
\hline Q68CQ4 & Digestive organ expansion factor homolog & 0.000267 & 1.882 \\
\hline P03950 & Angiogenin & $4.8 E-10$ & 1.7776 \\
\hline P13637 & Sodium/potassium-transporting ATPase subunit alpha-3 & 0.017893 & 1.742833 \\
\hline Q8WXD2 & Secretogranin-3 & $1.34 E-07$ & 1.71675 \\
\hline P06396 & Gelsolin & $3.3 E-46$ & 1.659898 \\
\hline Q8NBJ4 & Golgi membrane protein 1 & $7.61 E-08$ & 1.6227 \\
\hline Q96KN2 & Beta-Ala-His dipeptidase & $1.18 E-06$ & 1.588538 \\
\hline P02775 & Platelet basic protein & $1.22 E-17$ & 1.544688 \\
\hline P06727 & Apolipoprotein A-IV & 0 & 1.529316 \\
\hline P01023 & Alpha-2-macroglobulin & $1.85 E-68$ & 1.506488 \\
\hline Q14624 & Inter-alpha-trypsin inhibitor heavy chain $\mathrm{H} 4$ & $4.2 E-152$ & 1.503549 \\
\hline P02776 & Platelet factor 4 & $1.49 E-56$ & 1.487591 \\
\hline Q7Z2Y8 & Interferon-induced very large GTPase 1 & 0.047372 & 1.4735 \\
\hline P29122 & Proprotein convertase subtilisin/kexin type 6 & 0.002827 & 1.47275 \\
\hline P05154 & Plasma serine protease inhibitor & $1.09 E-06$ & 1.446654 \\
\hline P14618 & Pyruvate kinase PKM & 0.005908 & 1.444167 \\
\hline P06889 & Ig lambda chain V-IV region MOL & $9.86 E-05$ & 1.4295 \\
\hline P01857 & Ig gamma-1 chain $\mathrm{C}$ region & $4 E-180$ & 1.427066 \\
\hline P22792 & Carboxypeptidase $\mathrm{N}$ subunit 2 & $3.39 E-15$ & 1.348591 \\
\hline P01742 & Ig heavy chain V-I region EU & $3.44 E-19$ & 1.343614 \\
\hline P05090 & Apolipoprotein D & $1.43 E-66$ & 1.330211 \\
\hline P51884 & Lumican & $6.82 E-07$ & 1.323868 \\
\hline P01613 & Ig kappa chain $\mathrm{V}$-I region $\mathrm{Ni}$ & $6.17 E-05$ & 1.319958 \\
\hline P01860 & Ig gamma- 3 chain $\mathrm{C}$ region & $4.37 E-19$ & 1.318262 \\
\hline P14625 & Endoplasmin & 0.000738 & 1.3125 \\
\hline Q04756 & Hepatocyte growth factor activator & $4.34 E-05$ & 1.312333 \\
\hline P80108 & Phosphatidylinositol-glycan-specific phospholipase D & $6.28 E-16$ & 1.309714 \\
\hline P02787 & Serotransferrin & 0.03443 & 1.2721 \\
\hline P00450 & Ceruloplasmin & $1.43 E-27$ & 1.269935 \\
\hline P10720 & Platelet factor 4 variant & $1.65 E-05$ & 1.255714 \\
\hline P80748 & Ig lambda chain V-III region LOI & 0.003 & 1.24625 \\
\hline P01009 & Alpha-1-antitrypsin & $6.2 E-51$ & 1.245105 \\
\hline Q9NP79 & Coagulation factor XII & 0.001987 & 1.24225 \\
\hline P02671 & Retinoic acid receptor responder protein 2 & 0.008513 & 1.234583 \\
\hline P02679 & Ig kappa chain V-II region TEW & 0.024594 & 1.226038 \\
\hline P02675 & Kallistatin & 0.016269 & 1.223857 \\
\hline Q86XH2 & Complement Clq subcomponent subunit A & $8.72 E-05$ & 1.222116 \\
\hline P01020 & FERM and PDZ domain-containing protein 1 & $2.36 E-06$ & 1.212885 \\
\hline Q68CQ5 & Retinol-binding protein 4 & $4.81 E-08$ & 1.2112 \\
\hline \multicolumn{4}{|c|}{ Downregulated protein } \\
\hline Q02818 & Nucleobindin-1 & 0.002012 & 0.8295 \\
\hline Q9UK55 & Protein Z-dependent protease inhibitor & $2.62 E-11$ & 0.829081 \\
\hline P02656 & Apolipoprotein C-III & $3.32 E-34$ & 0.823015 \\
\hline P62258 & 14-3-3 protein epsilon & 0.04376 & 0.81975 \\
\hline
\end{tabular}


TABLE 3: Continued.

\begin{tabular}{|c|c|c|c|}
\hline Accession & Description & $P$ value & Ratio (mean) \\
\hline P01877 & Ig alpha- 2 chain $C$ region & 0.024488 & 0.817692 \\
\hline Q6Q788 & Apolipoprotein A-V & $5.25 E-08$ & 0.81769 \\
\hline P36980 & Complement factor $\mathrm{H}$-related protein 2 & 0.001599 & 0.815458 \\
\hline P35542 & Serum amyloid A-4 protein & $2.65 E-29$ & 0.813253 \\
\hline P01620 & Ig kappa chain V-III region SIE & $1.42 E-05$ & 0.800375 \\
\hline O14818 & Proteasome subunit alpha type-7 & 0.024316 & 0.794833 \\
\hline P18428 & Lipopolysaccharide-binding protein & $4.26 E-75$ & 0.789371 \\
\hline P04438 & Ig heavy chain V-II region SESS & 0.044412 & 0.78775 \\
\hline P49721 & Proteasome subunit beta type- 2 & 0.026571 & 0.7765 \\
\hline P04196 & Histidine-rich glycoprotein & $6.01 E-28$ & 0.775008 \\
\hline P02649 & Apolipoprotein E & 0 & 0.75853 \\
\hline Q86UD1 & Out at first protein homolog & $7.29 E-08$ & 0.755267 \\
\hline P04211 & Ig lambda chain $\mathrm{V}$ region $4 \mathrm{~A}$ & $1.19 E-05$ & 0.751667 \\
\hline P0DJI9 & Serum amyloid A-2 protein & $7.71 E-05$ & 0.744667 \\
\hline P67936 & Tropomyosin alpha- 4 chain & 0.0005 & 0.74375 \\
\hline Q8NDV3 & Structural maintenance of chromosomes protein $1 \mathrm{~B}$ & 0.000726 & 0.741833 \\
\hline P62158 & Calmodulin & 0.005327 & 0.733667 \\
\hline Q16610 & Extracellular matrix protein 1 & $5.58 E-10$ & 0.731882 \\
\hline Q92954 & Proteoglycan 4 & $7.15 E-12$ & 0.728857 \\
\hline P59665 & Neutrophil defensin 1 & 0.000151 & 0.7177 \\
\hline P20742 & Pregnancy zone protein & $4.88 E-71$ & 0.696948 \\
\hline P02741 & C-reactive protein & $2.7 E-173$ & 0.677154 \\
\hline Q71U36 & Tubulin alpha-1A chain & 0.000833 & 0.657333 \\
\hline P02751 & Fibronectin & 0 & 0.635439 \\
\hline P08519 & Apolipoprotein(a) & $7.96 E-09$ & 0.56335 \\
\hline
\end{tabular}

reference pathways in KEGG database to identify significantly enriched metabolic pathways or signal transduction pathways. In total, 47, 58, and 20 significantly enriched pathways were obtained in SANFH versus healthy controls (Table 6), SANFH-TCM versus healthy controls (Table 7), and SANFH-TCM versus SANFH (Table 8$)(P<0.05)$, respectively. The top listed five pathways were Alzheimer's disease, salivary secretion, Huntington's disease, Parkinson's disease, and oxidative phosphorylation in SANFH versus healthy controls (Table 6); mineral absorption, PPAR signaling pathway, chemokine signaling pathway, adrenergic signaling in cardiomyocytes, and neurotrophin signaling pathway in SANFH-TCM versus healthy controls (Table 7); and chemokine signaling pathway, platelet activation, cytokinecytokine receptor interaction, glycosylphosphatidylinositol(GPI-) anchor biosynthesis, and beta-alanine metabolism in SANFH-TCM versus SANFH (Table 8$)(P<0.03)$, respectively. The predicted biomarker LPE was involved in the enriched pathway of Alzheimer's disease in both SANFH versus healthy and SANFH-TCM versus healthy controls. In SANFH-TCM versus healthy controls, LPA was involved in the enriched pathway of PPAR signaling pathway; fibronectin was involved in the enriched pathway of pathways in cancer, small-cell lung cancer, and bacterial invasion of epithelial cells. Fibrinogen alpha, fibrinogen beta, and fibrinogen gamma were involved in the enriched pathway of platelet activation in both SANFH-TCM versus healthy controls and SANFH-TCM versus SANFH. In SANFH-TCM versus SANFH, fibronectin was involved in the enriched pathway of regulation of actin cytoskeleton, and fibrinogen gamma was also involved in the enriched pathway of Staphylococcus aureus infection.

\section{Discussion}

This is the first study to reveal proteins associated with steroid-induced avascular necrosis of the femoral head with or without Traditional Chinese Medicine treatment on the proteome level. MRM was used to add confidence to the results obtained by iTRAQ and was attempted for validating 8 proteins (fibrinogen alpha, fibrinogen beta, fibrinogen gamma, fibronectin, C-reactive protein, apolipoprotein A, apolipoprotein $\mathrm{D}$, and apolipoprotein $\mathrm{E}$ ).

Currently, the pathogenesis theories on femoral head necrosis mainly include [27, 28]: theory of osteoporosis; theory of vascular wall damage or compression and theory of blood lipid disorder [29]; theory of high intraosseous pressure; theory of intravascular coagulation; theory of secondary collision; and so forth [30]. Secondary collision theory [31] considers that osteonecrosis of the femoral head 
TABLE 4: Differentially expressed protein between SANFH-TCM and SANFH.

\begin{tabular}{|c|c|c|c|}
\hline Accession & Description & $P$ value & Ratio (mean) \\
\hline \multicolumn{4}{|c|}{ Upregulated protein } \\
\hline Q9NP78 & ATP-binding cassette sub-family B member 9 & $7.38 E-10$ & 21.82029412 \\
\hline Q86XH1 & IQ and AAA domain-containing protein 1 & 0.000343733 & 13.86725 \\
\hline P02671 & Fibrinogen alpha chain & 0 & 13.65918665 \\
\hline P02675 & Fibrinogen beta chain & 0 & 13.64325401 \\
\hline P02679 & Fibrinogen gamma chain & 0 & 13.23321597 \\
\hline P01019 & Angiotensinogen & 0.000000129 & 2.391730769 \\
\hline Q68CQ4 & Digestive organ expansion factor homolog & 0.0000351 & 2.26525 \\
\hline P03950 & Angiogenin & 0.00000196 & 2.0039 \\
\hline P35527 & Keratin, type I cytoskeletal 9 & $3.95 E-11$ & 1.928576923 \\
\hline Q8WXD2 & Secretogranin-3 & 0.000728124 & 1.91025 \\
\hline P27918 & Properdin & $1.39 E-40$ & 1.763869048 \\
\hline P14618 & Pyruvate kinase PKM & 0.002960903 & 1.632333333 \\
\hline P05154 & Plasma serine protease inhibitor & $2.03 E-12$ & 1.607923077 \\
\hline Q04756 & Hepatocyte growth factor activator & $2.81 E-08$ & 1.590333333 \\
\hline P02775 & Platelet basic protein & $2.34 E-18$ & 1.56775 \\
\hline P02776 & Platelet factor 4 & $3.43 E-84$ & 1.559232955 \\
\hline P02749 & Beta-2-glycoprotein 1 & 0.0000322 & 1.548 \\
\hline Q96KN2 & Beta-Ala-His dipeptidase & 0.0000169 & 1.533115385 \\
\hline P01023 & Alpha-2-macroglobulin & $1.1 E-62$ & 1.519228916 \\
\hline P06727 & Apolipoprotein A-IV & 0 & 1.4910721 \\
\hline P06396 & Gelsolin & $7.08 E-33$ & 1.485481481 \\
\hline P01769 & Ig heavy chain V-III region GA & 0.009729195 & 1.45675 \\
\hline P10720 & Platelet factor 4 variant & 0.000000465 & 1.450190476 \\
\hline P05090 & Apolipoprotein D & $5.92 E-70$ & 1.385849624 \\
\hline P19823 & Inter-alpha-trypsin inhibitor heavy chain $\mathrm{H} 2$ & $1.59 E-76$ & 1.376936508 \\
\hline P01871 & Ig mu chain $\mathrm{C}$ region & $1.12 E-123$ & 1.37344898 \\
\hline P01616 & Ig kappa chain V-II region MIL & 0.004694041 & 1.35375 \\
\hline P34096 & Ribonuclease 4 & 0.016807995 & 1.3485 \\
\hline P29122 & Proprotein convertase subtilisin/kexin type 6 & 0.007174928 & 1.3275 \\
\hline P80108 & Phosphatidylinositol-glycan-specific phospholipase D & $1.54 E-12$ & 1.320666667 \\
\hline P55056 & Apolipoprotein C-IV & 0.0000081 & 1.3169 \\
\hline O95445 & Apolipoprotein M & 0.00000275 & 1.314954545 \\
\hline Q9UHG3 & Prenylcysteine oxidase 1 & 0.00000266 & 1.305045455 \\
\hline P08603 & Complement factor $\mathrm{H}$ & $8.17 E-39$ & 1.296578143 \\
\hline P02787 & Serotransferrin & 0.002337342 & 1.2947 \\
\hline P05164 & Myeloperoxidase & 0.020349711 & 1.282 \\
\hline Q8WWA0 & Intelectin-1 & 0.0000227 & 1.2735 \\
\hline P29622 & Kallistatin & 0.0000069 & 1.267285714 \\
\hline Q9NP79 & Immunoglobulin J chain & $4.06 E-10$ & 1.260973684 \\
\hline Q86XH2 & CD5 antigen-like & $3 E-31$ & 1.248355422 \\
\hline P02671 & Plasma kallikrein & $6.95 E-08$ & 1.236383333 \\
\hline P02675 & Serum amyloid P-component & $1.03 E-24$ & 1.236112319 \\
\hline P02679 & Inter-alpha-trypsin inhibitor heavy chain $\mathrm{H} 1$ & $1.7 E-30$ & 1.230389423 \\
\hline P01019 & Alpha-actinin-4 & 0.045621384 & 1.23 \\
\hline \multicolumn{4}{|c|}{ Downregulated protein } \\
\hline P04217 & Alpha-1B-glycoprotein & 0.0000256 & 0.826346154 \\
\hline P01613 & Ig kappa chain $\mathrm{V}$-I region $\mathrm{Ni}$ & 0.010289928 & 0.825583333 \\
\hline Q16610 & Extracellular matrix protein 1 & 0.000000945 & 0.821529412 \\
\hline Q92954 & Proteoglycan 4 & $1.05 E-09$ & 0.8145 \\
\hline
\end{tabular}


TABLE 4: Continued.

\begin{tabular}{|c|c|c|c|}
\hline Accession & Description & $P$ value & Ratio (mean) \\
\hline Q02818 & Nucleobindin-1 & 0.000247875 & 0.813125 \\
\hline P01742 & Ig heavy chain V-I region EU & $1.22 E-08$ & 0.803428571 \\
\hline P04434 & Ig kappa chain V-III region VH (Fragment) & 0.030092513 & 0.802166667 \\
\hline P55774 & $\mathrm{C}-\mathrm{C}$ motif chemokine 18 & 0.003307656 & 0.79825 \\
\hline Q9HDC9 & Adipocyte plasma membrane-associated protein & 0.00000847 & 0.798083333 \\
\hline P01011 & Alpha-1-antichymotrypsin & $7.56 E-13$ & 0.796217391 \\
\hline P01621 & Ig kappa chain V-III region NG9 (Fragment) & 0.0000675 & 0.795 \\
\hline P01717 & Ig lambda chain V-IV region Hil & 0.0000608 & 0.78905 \\
\hline P04196 & Histidine-rich glycoprotein & $2.81 E-26$ & 0.783991667 \\
\hline P04433 & Ig kappa chain V-III region VG (Fragment) & 0.00000651 & 0.783357143 \\
\hline P35542 & Serum amyloid A-4 protein & $1.77 E-40$ & 0.752563218 \\
\hline P0DJI8 & Serum amyloid A-1 protein & $4.33 E-11$ & 0.748036765 \\
\hline P27824 & Calnexin & 0.038086684 & 0.73825 \\
\hline P00740 & Coagulation factor IX & $6.16 E-23$ & 0.733622222 \\
\hline Q9UGM5 & Fetuin-B & 0.00451302 & 0.721833333 \\
\hline P0C0L4 & Complement C4-A & $4.74 E-14$ & 0.71725 \\
\hline Q08380 & Galectin-3-binding protein & $9.69 E-59$ & 0.713721805 \\
\hline P04438 & Ig heavy chain V-II region SESS & 0.039314686 & 0.70425 \\
\hline P20742 & Pregnancy zone protein & $9.73 E-65$ & 0.698695238 \\
\hline P13645 & Keratin, type I cytoskeletal 10 & $1.17 E-19$ & 0.69635 \\
\hline Q86UD1 & Out at first protein homolog & $3.02 E-09$ & 0.694666667 \\
\hline P02751 & Fibronectin & 0 & 0.692870958 \\
\hline P04208 & Ig lambda chain V-I region WAH & 0.000226793 & 0.6685 \\
\hline P01861 & Ig gamma- 4 chain $\mathrm{C}$ region & $2.47 E-08$ & 0.655777778 \\
\hline P18428 & Lipopolysaccharide-binding protein & $5.83 E-130$ & 0.640994118 \\
\hline P49721 & Proteasome subunit beta type- 2 & 0.019809794 & 0.6185 \\
\hline P25789 & Proteasome subunit alpha type- 4 & 0.00601102 & 0.609 \\
\hline P01743 & Ig heavy chain V-I region HG3 & 0.0000275 & 0.607136364 \\
\hline P01620 & Ig kappa chain V-III region SIE & $1.87 E-11$ & 0.5894375 \\
\hline P02452 & Collagen alpha-1(I) chain & 0.000916641 & 0.4901 \\
\hline P02741 & C-reactive protein & $1.19 E-243$ & 0.445641414 \\
\hline P01714 & Ig lambda chain V-III region SH & $1.91 E-09$ & 0.442666667 \\
\hline P0DJI9 & Serum amyloid A-2 protein & $1.16 E-08$ & 0.424595238 \\
\hline
\end{tabular}

is multifactor disease and it is related to genetic susceptibility factor and exposure to specific risk factors. The occurrence of femoral head necrosis is the collusion result of posterior acquired factors and genetic predisposing factor. Clinical studies also indicate that not all patients that had taken high dose hormone for a long time will suffer from femoral head necrosis and only $10 \%$ of patients will be attacked by femoral head necrosis. Though there are many clinical and basis studies about femoral head avascular necrosis, its specific pathophysiological mechanism is still not determined [10,14]. The beginning of proteomic technology applying in femoral head necrosis is relatively late and there are rare reports. The proteomics study of femoral head necrosis will be helpful to explain the pathological physiology mechanism of femoral head necrosis.

By using meprednisone to induce chicken femoral head necrosis, Li et al. [32] found that there are adipose tissue proliferation and new bone formation through the histological examination; by two-dimensional electrophoresis, 13 protein expression differences were found. Among them, 9 kinds of proteins were downregulated 3 times after hormone treatment, which were serum amyloid P-component precursor, zinc finger protein 28, endothelial zinc finger protein $71, \mathrm{~T}$ box transcription factor 3, cyclin-dependent kinase inhibitor 1 , myosin $1 \mathrm{D}$, dimethylaniline monooxygenase, and two kinds of unknown proteins. However, the animal species were 


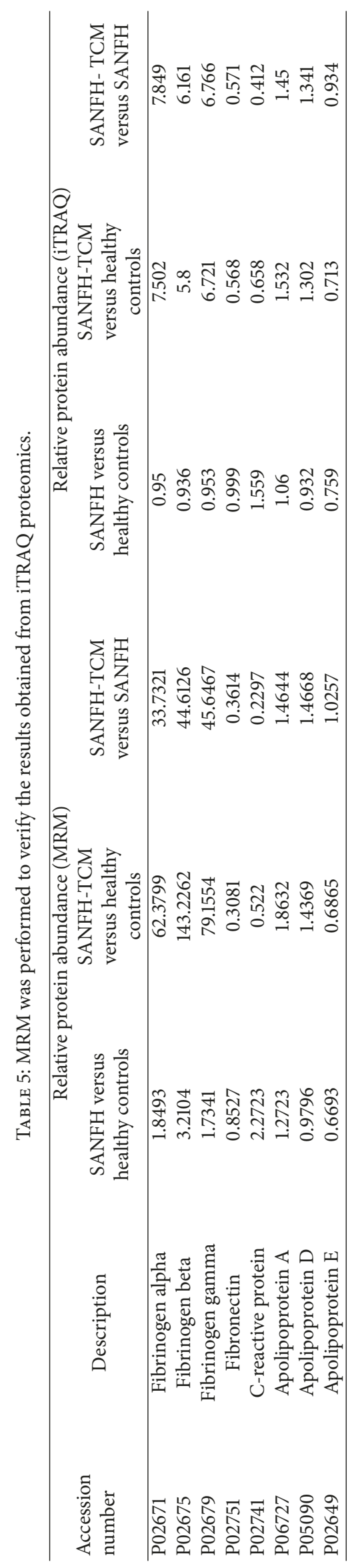



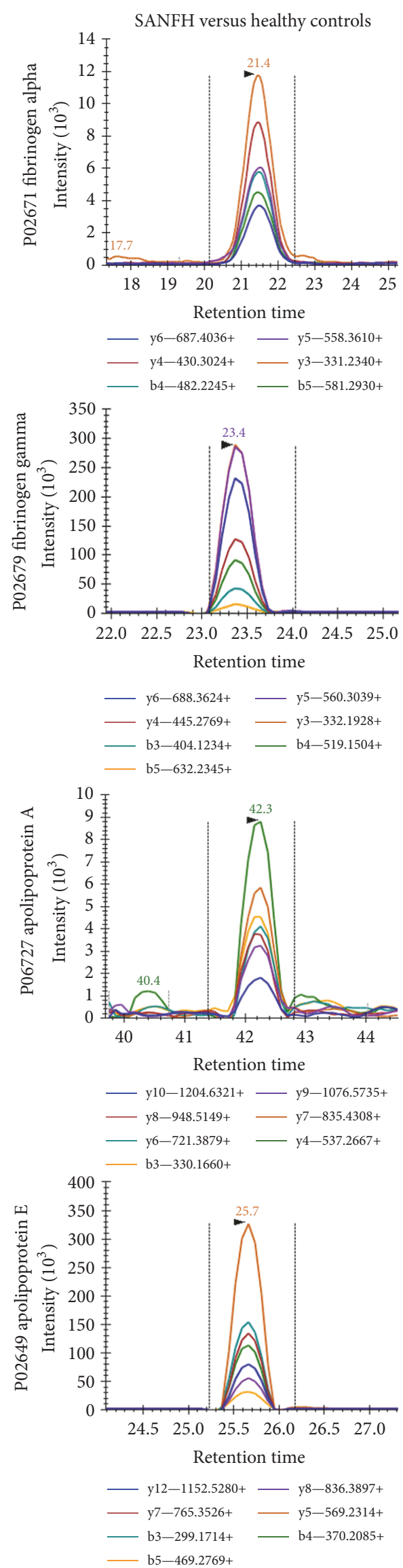
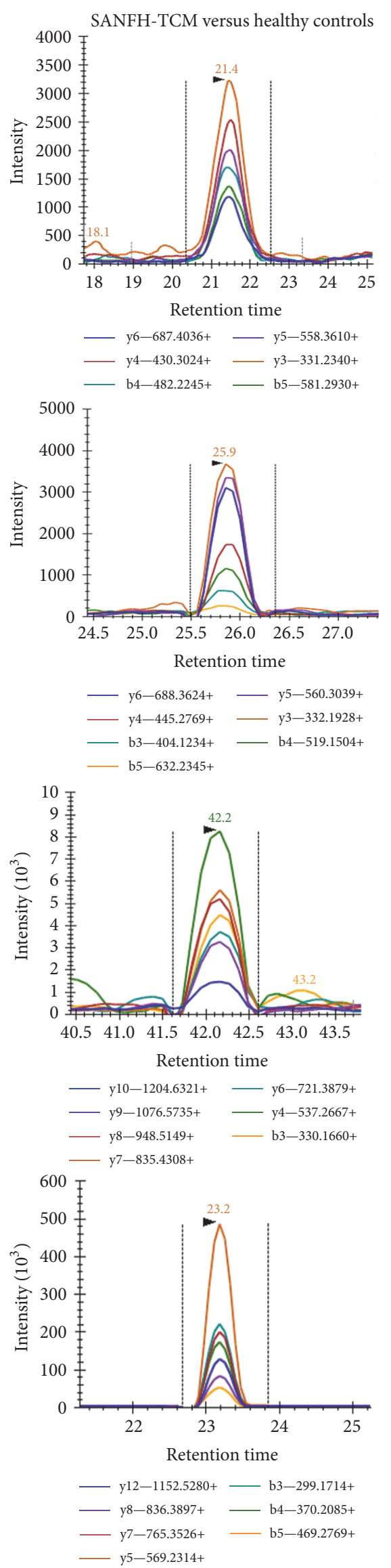

FIgURE 1: Continued.
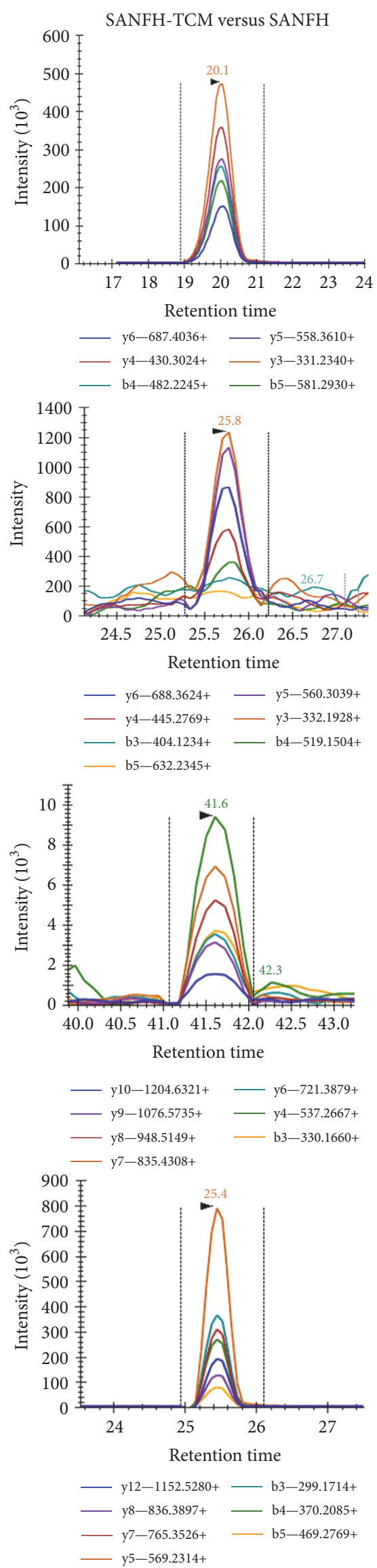

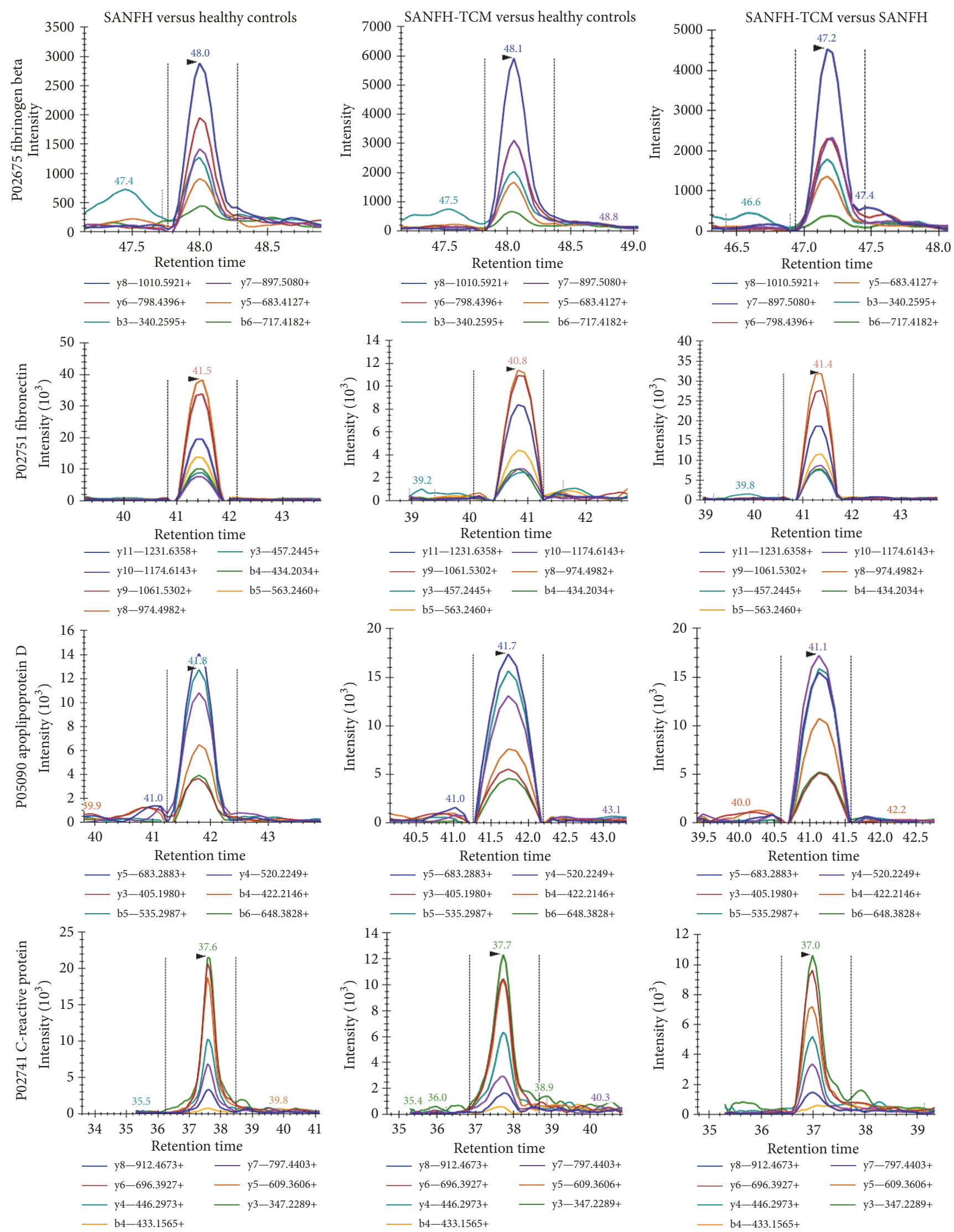

FIGURE 1: MRM quantification of results obtained from iTRAQ proteomics. MRM was performed to verify the different expressions of selected proteins including fibrinogen alpha, fibrinogen beta, and fibrinogen gamma, fibronectin, apolipoprotein A (LPA), apolipoprotein D (LPD), and apolipoprotein E (LPD), and C-reaction protein in SANFH versus healthy controls, SANFH-TCM versus healthy controls, and SANFHTCM versus SANFH. 
TABLE 6: Differently enriched pathways were obtained in SANFH versus healthy controls.

\begin{tabular}{|c|c|c|c|c|c|}
\hline Pathway_acc & Pathway_Name & $P$ value & $\begin{array}{c}\text { Protein in } \\
\text { Background }\end{array}$ & $\begin{array}{l}\text { Protein in } \\
\text { Diff Exp }\end{array}$ & Protein list \\
\hline hsa05010 & Alzheimer's disease & 0.015362 & 7 & 4 & $\begin{array}{c}\mathrm{P} 25705, \mathrm{P} 02649, \mathrm{P} 62158, \\
\text { P06576 }\end{array}$ \\
\hline hsa04970 & Salivary secretion & 0.032411 & 5 & 3 & P62158, P04220, P13637, \\
\hline hsa05016 & Huntington's disease & 0.057318 & 6 & 3 & P25705, P12235, P06576, \\
\hline hsa05012 & Parkinson's disease & 0.057318 & 6 & 3 & P25705, P12235, P06576, \\
\hline hsa00190 & Oxidative phosphorylation & 0.070274 & 3 & 2 & P25705, P06576, \\
\hline hsa04261 & Adrenergic signaling in cardiomyocytes & 0.088785 & 7 & 3 & P67936, P62158, P13637, \\
\hline hsa04915 & Estrogen signaling pathway & 0.125873 & 4 & 2 & P62158, P14625, \\
\hline hsa04020 & Calcium signaling pathway & 0.125873 & 4 & 2 & P12235, P62158, \\
\hline hsa04974 & Protein digestion and absorption & 0.125873 & 4 & 2 & P13637, P02452, \\
\hline hsa04260 & Cardiac muscle contraction & 0.125873 & 4 & 2 & P67936, P13637, \\
\hline hsa04961 & $\begin{array}{l}\text { Endocrine and other } \\
\text { factor-regulated calcium reabsorption }\end{array}$ & 0.162907 & 1 & 1 & P13637, \\
\hline hsa04964 & Proximal tubule bicarbonate reclamation & 0.162907 & 1 & 1 & P13637, \\
\hline hsa04960 & Aldosterone-regulated sodium reabsorption & 0.162907 & 1 & 1 & P13637, \\
\hline hsa04070 & Phosphatidylinositol signaling system & 0.162907 & 1 & 1 & P62158, \\
\hline hsa04744 & Phototransduction & 0.162907 & 1 & 1 & P62158, \\
\hline hsa04976 & Bile secretion & 0.162907 & 1 & 1 & P13637, \\
\hline hsa05130 & Pathogenic Escherichia coli infection & 0.167478 & 9 & 3 & $\begin{array}{l}\text { Q71U36, P63104, } \\
\text { P68366, }\end{array}$ \\
\hline hsa04918 & Thyroid hormone synthesis & 0.188181 & 5 & 2 & $\mathrm{P} 14625, \mathrm{P} 13637$, \\
\hline hsa04971 & Gastric acid secretion & 0.188181 & 5 & 2 & P62158, P13637, \\
\hline hsa04540 & Gap junction & 0.253612 & 6 & 2 & Q71U36, P68366, \\
\hline hsa04972 & Pancreatic secretion & 0.299618 & 2 & 1 & P13637, \\
\hline hsa04720 & Long-term potentiation & 0.299618 & 2 & 1 & P62158, \\
\hline hsa04911 & Insulin secretion & 0.299618 & 2 & 1 & P13637, \\
\hline hsa05214 & Glioma & 0.299618 & 2 & 1 & P62158, \\
\hline hsa04978 & Mineral absorption & 0.299618 & 2 & 1 & P13637, \\
\hline hsa04973 & Carbohydrate digestion and absorption & 0.299618 & 2 & 1 & P13637, \\
\hline hsa04014 & Ras signaling pathway & 0.299618 & 2 & 1 & P62158, \\
\hline hsa04270 & Vascular smooth muscle contraction & 0.299618 & 2 & 1 & P62158, \\
\hline hsa04910 & Insulin signaling pathway & 0.299618 & 2 & 1 & P62158, \\
\hline hsa05031 & Amphetamine addiction & 0.299618 & 2 & 1 & P62158, \\
\hline hsa04750 & Inflammatory mediator regulation of TRP channels & 0.299618 & 2 & 1 & P62158, \\
\hline hsa04912 & GnRH signaling pathway & 0.299618 & 2 & 1 & P62158, \\
\hline hsa05152 & Tuberculosis & 0.319543 & 7 & 2 & P18428, P62158, \\
\hline hsa05150 & Staphylococcus aureus infection & 0.334256 & 18 & 4 & $\begin{array}{l}\text { P00751, P0C0L4, P13645, } \\
\text { P02747 }\end{array}$ \\
\hline hsa04120 & Ubiquitin mediated proteolysis & 0.357215 & 13 & 3 & P01742, P01781, P01743, \\
\hline hsa04114 & Oocyte meiosis & 0.3841 & 8 & 2 & P63104, P62158, \\
\hline hsa04919 & Thyroid hormone signaling pathway & 0.41429 & 3 & 1 & P13637, \\
\hline hsa04916 & Melanogenesis & 0.41429 & 3 & 1 & P62158, \\
\hline hsa04064 & NF-kappa B signaling pathway & 0.41429 & 3 & 1 & P18428, \\
\hline hsa04728 & Dopaminergic synapse & 0.41429 & 3 & 1 & P62158, \\
\hline hsa04621 & NOD-like receptor signaling pathway & 0.41429 & 3 & 1 & P14625, \\
\hline hsa05215 & Prostate cancer & 0.41429 & 3 & 1 & P14625, \\
\hline
\end{tabular}


TABLE 6: Continued.

\begin{tabular}{lccccc}
\hline Pathway_acc & Pathway_Name & P value & $\begin{array}{c}\text { Protein in } \\
\text { Background }\end{array}$ & $\begin{array}{c}\text { Protein in } \\
\text { Diff Exp }\end{array}$ & Protein list \\
\hline hsa04740 & Olfactory transduction & 0.41429 & 3 & 1 & P62158, \\
hsa04620 & Toll-like receptor signaling pathway & 0.41429 & 3 & 1 & P18428, \\
hsa04713 & Circadian entrainment & 0.41429 & 3 & 1 & P62158, \\
hsa03320 & PPAR signaling pathway & 0.445992 & 9 & 2 & P08519, Q6Q788, \\
hsa05133 & Pertussis & 0.45325 & 15 & 3 & P0C0L4, P62158, P02747, \\
\hline
\end{tabular}

Note. Italic font indicated the candidate protein.

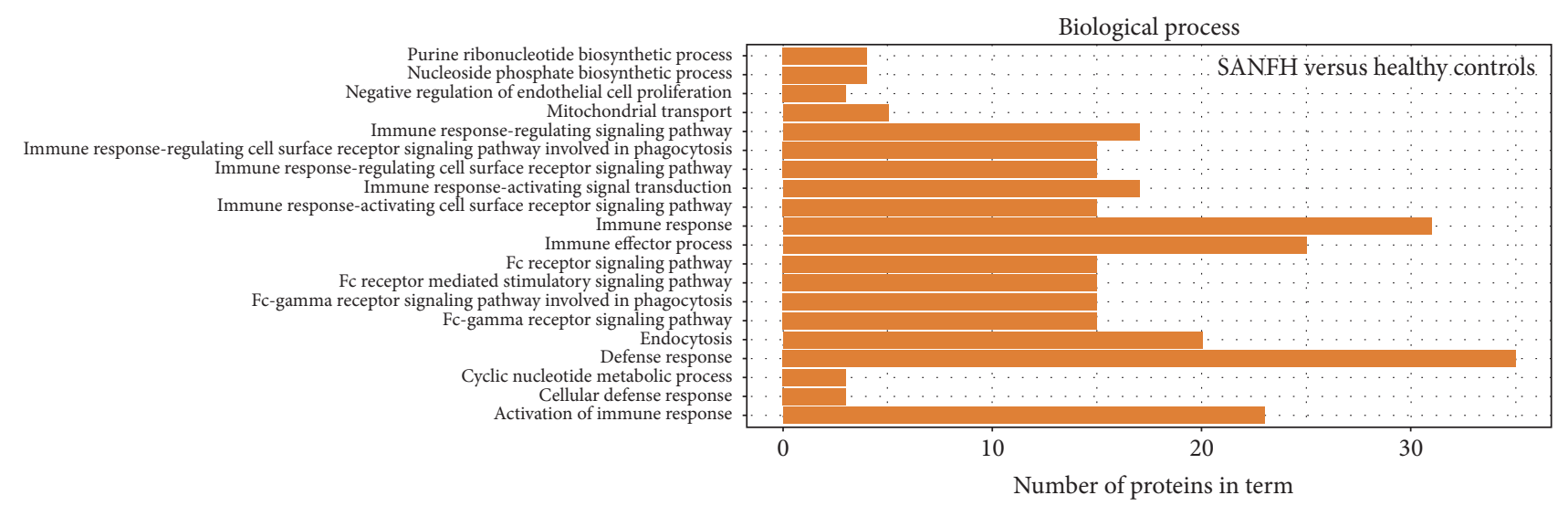

Cellular component

Proton-transporting two-sector ATPase complex, catalytic domain roton-transporting two-sector ATPase complex Proton-transporting ATP synthase complex
Pigment granule Organelle inner membrane Organelle inner membrane
Mitochondrion
Mitochondrial proton-transporting ATP synthase complex
Mitochondrial protein complex Mitochondrial protein complex
Mitochondrial part Mitochondrial membrane part
Mitochondrial membrane Mitochondrial inner membrane Mitochondrial envelope Microtuble
Melanosome Melanosome
Inner mitochondrial membrane protein complex
Fibrillar collagen trimer Complex of collagen trimers Banded collagen fibril

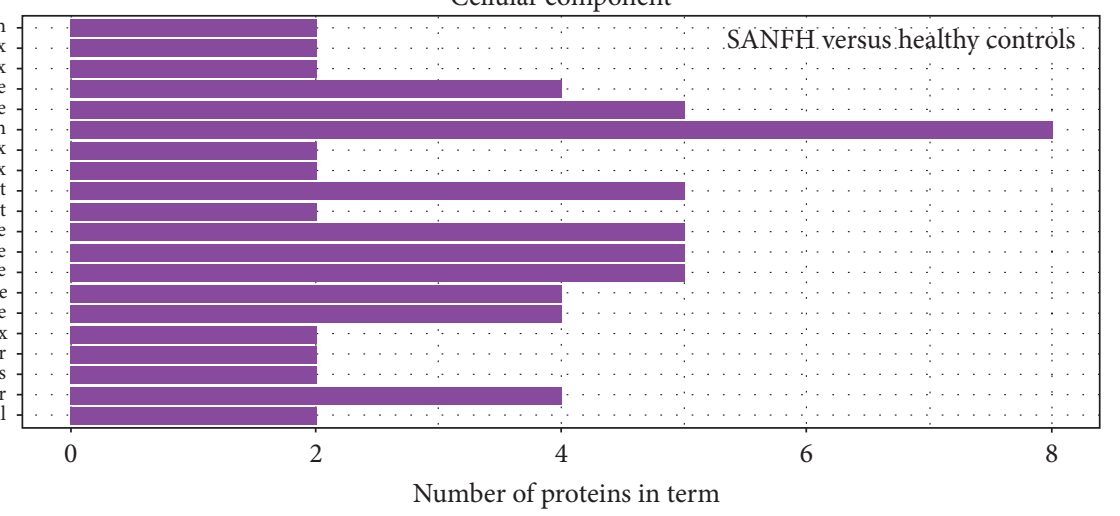

Number of proteins in term

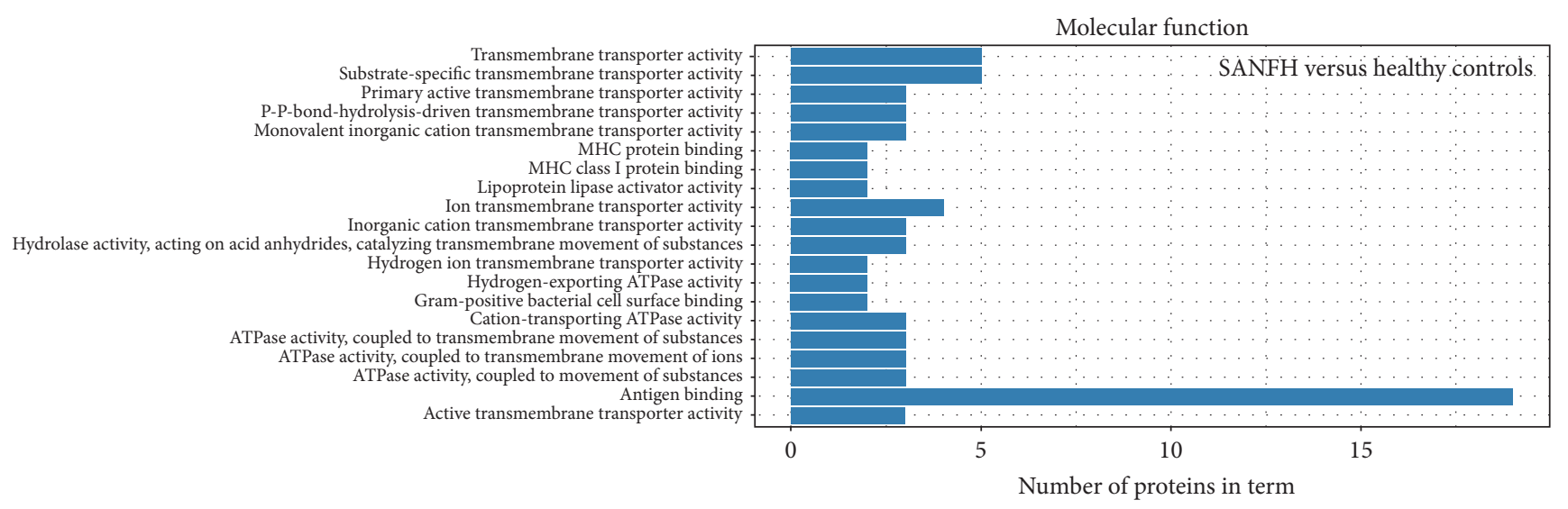

FIGURE 2: GO analysis of differentially expressed proteins between SANFH and healthy controls. The significantly enriched GO terms concerning biological process, cellular component, and molecular function were shown. 

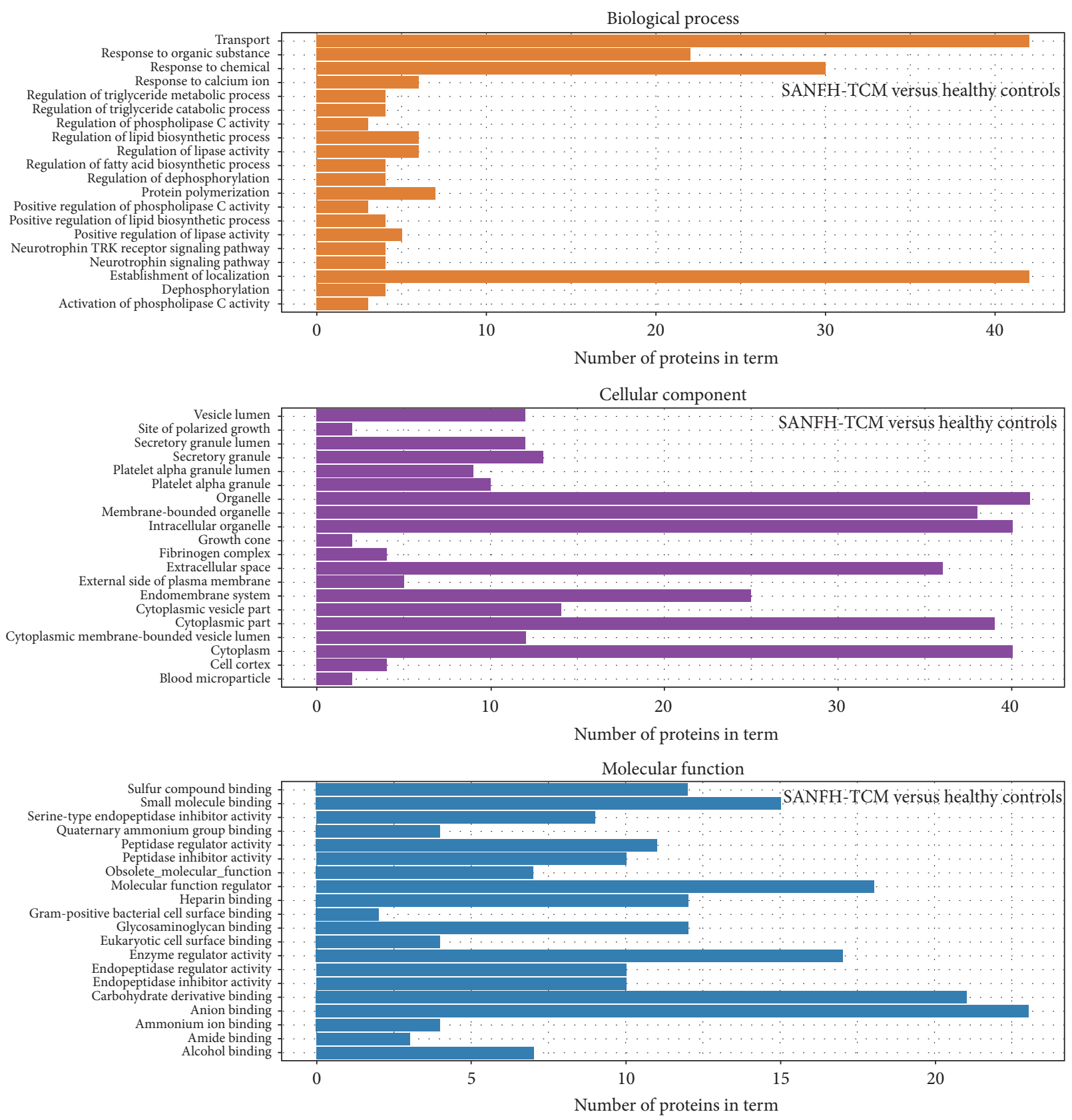

FIGURE 3: GO analysis of differentially expressed proteins between SANFH-TCM and healthy controls. The significantly enriched GO terms concerning biological process, cellular component and molecular function were shown.

different, the cases in the clinical study were few, and the pathogenesis was different, so they lacked comparability and the study results were also different, without representativeness, so they were not sufficient to explain the pathogenesis of femoral head necrosis.

Considering the sampling of bone tissue is an invasive operation, which will bring regional trauma for patients increasing their suffering, the sampling of serum is easier and is also easy for patients to accept. There are few studies on femoral head necrosis. Researchers $[3,33]$ conducted serum proteomics study on 11 patients with drinking, hormone treatment, or specific femoral head necrosis (3 female and
8 male) and they found 8 protein differential points. Comparing with the serum of healthy volunteers, the serum of patients with femoral head had higher kininogen 1 variant, complement factor $\mathrm{C} 3$ precursor, and complement factor $\mathrm{H}$. Besides, patients with femoral head necrosis had significant lower apolipoprotein A-IV precursor, antithrombin III chain $\mathrm{B}$, and gelsolin isoform $\alpha$ precursor.

In the present study, we further suggested that the serum amyloid A-2 (SAA2), Ig lambda, sodium/potassiumtransporting ATPase subunit alpha-3 (ATP1A3), calciumbinding mitochondrial carrier protein Aralar1 (SLC25A12), properdin, KRT9, LPA, TPM4, ABCB9, fibrinogen alpha, 

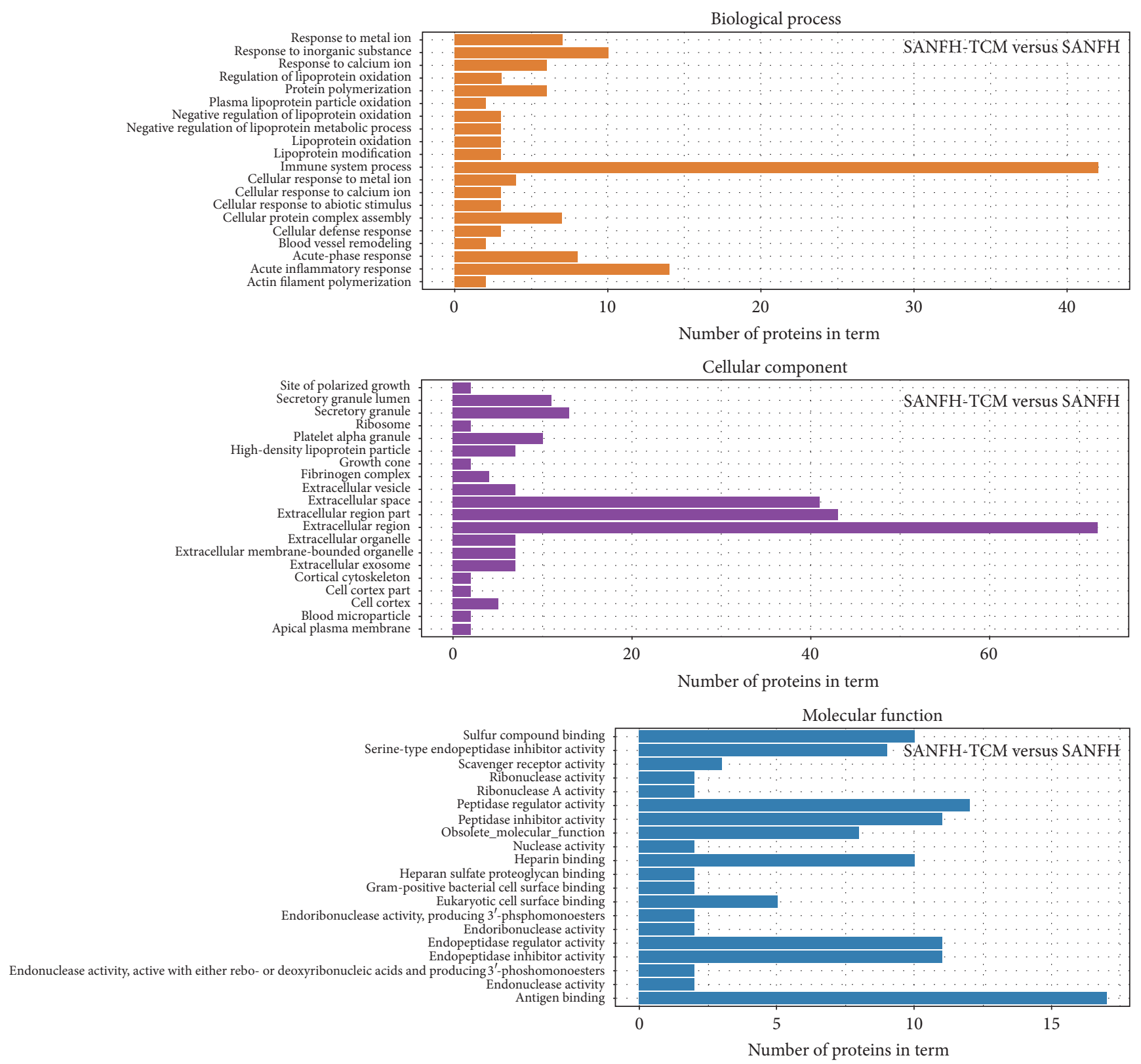

FIGURE 4: GO analysis of differentially expressed proteins between SANFH-TCM and SANFH. The significantly enriched GO terms concerning biological process, cellular component, and molecular function were shown.

fibrinogen gamma, fibrinogen beta, CRP, TUBA1A, fibronectin, IQCA1, SAA2, and collagen alpha-1 were potential serum marker by iTRAQ and further confirmed the changes of fibrinogen alpha, fibrinogen beta, fibrinogen gamma, fibronectin, C-reactive protein, apolipoprotein A, apolipoprotein $\mathrm{D}$, and apolipoprotein $\mathrm{E}$. The predicted biomarker LPE was involved in the enriched pathway of Alzheimer's disease; LPA was involved in the enriched pathway of PPAR signaling pathway; fibronectin was involved in the enriched pathway of pathways in cancer, small-cell lung cancer, and bacterial invasion of epithelial cells; fibrinogen alpha, fibrinogen beta, and fibrinogen gamma were involved in the enriched pathway of platelet activation; fibronectin was involved in the enriched pathway of regulation of actin cytoskeleton, and fibrinogen gamma was also involved in the enriched pathway of Staphylococcus aureus infection. Consistently, it has demonstrated that apolipoprotein A1 is potential risk for femoral head necrosis [34-36]. Fibronectin related to extracellular matrix integrity and adhesion is also an identified serum marker for broiler chickens with femoral head necrosis [35]. Fibrinogen beta was candidate biomarker of infection and inflammation [37] and femoral head necrosis [35]. CRP is an acute-phase protein, negatively correlated with adiponectin level in osteonecrosis of the femoral head [38].

In conclusion, our results identified 74 differentially expressed proteins between SANTH-TCM and healthy controls, 62 proteins between SANFH and healthy controls, 


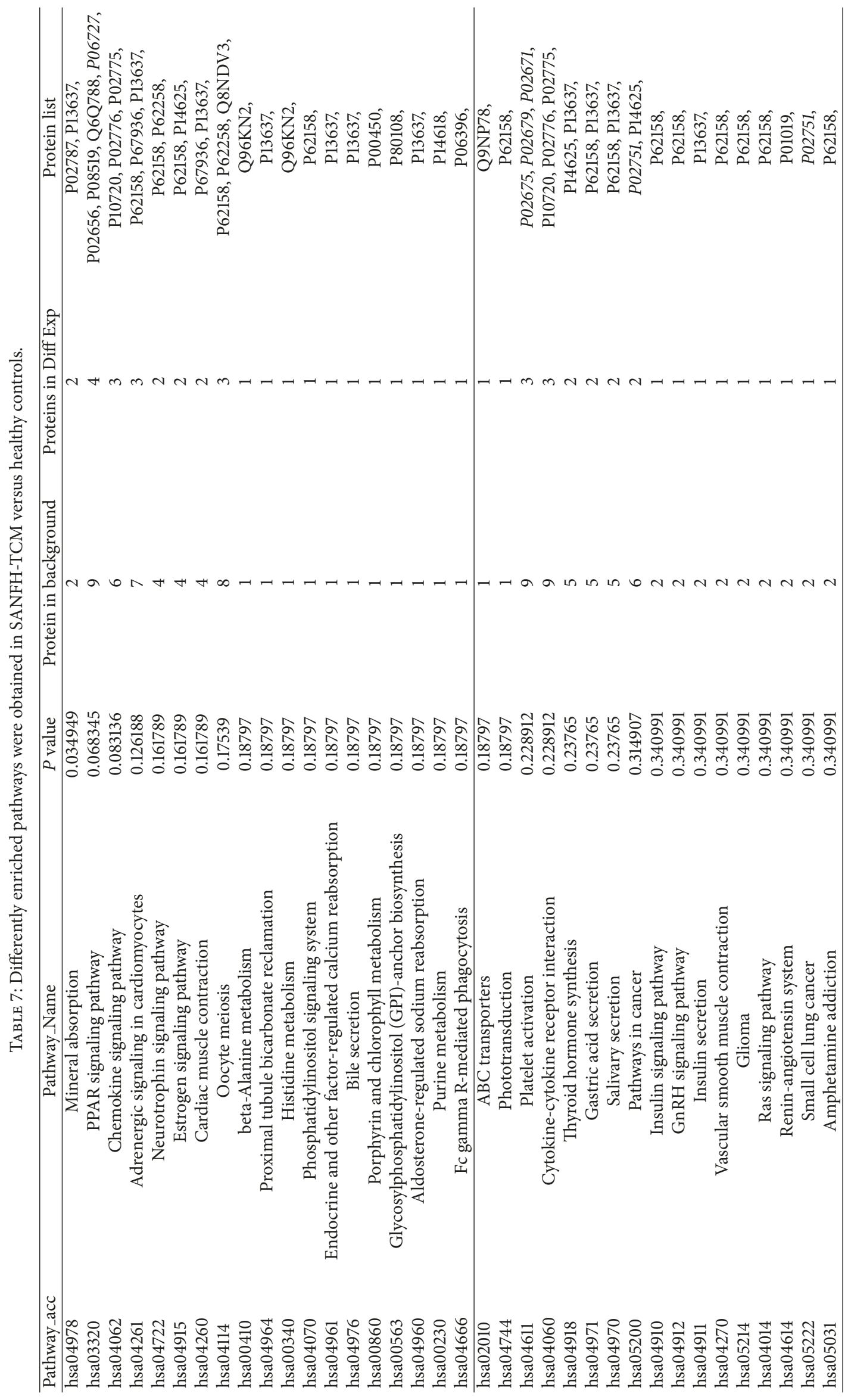




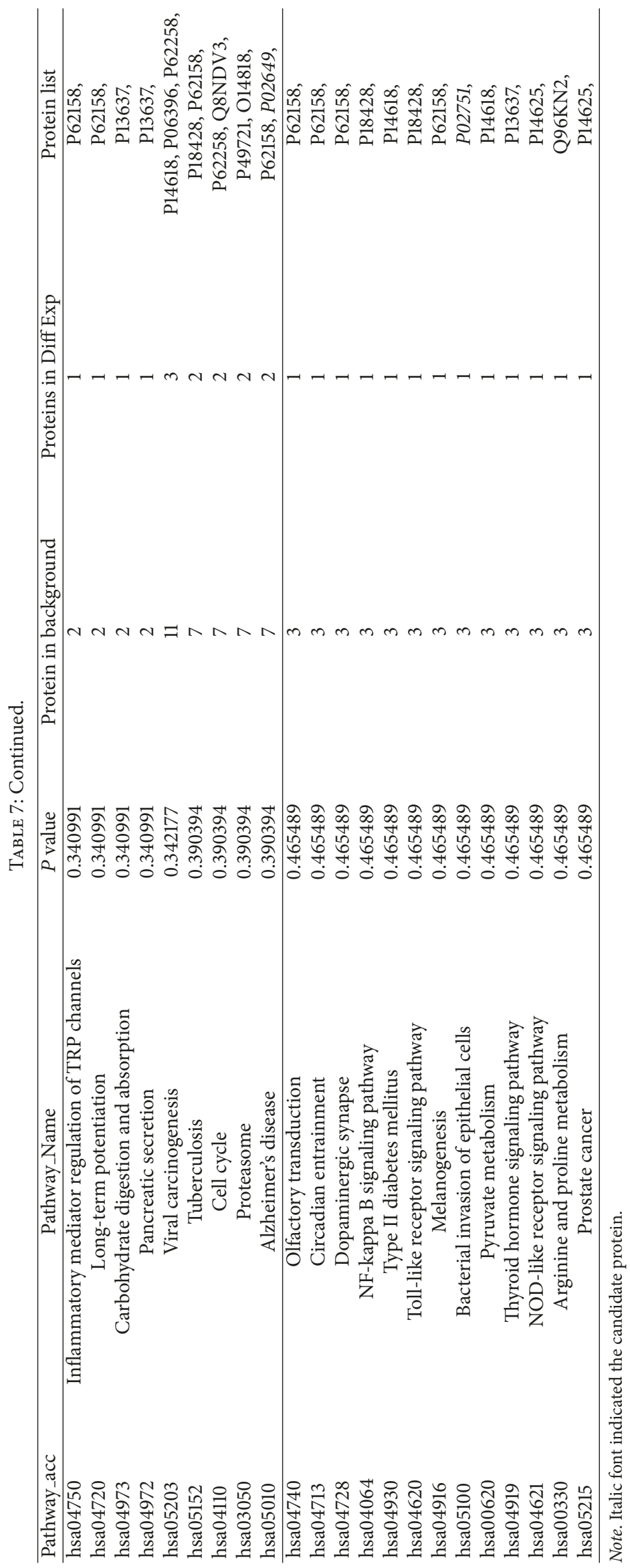




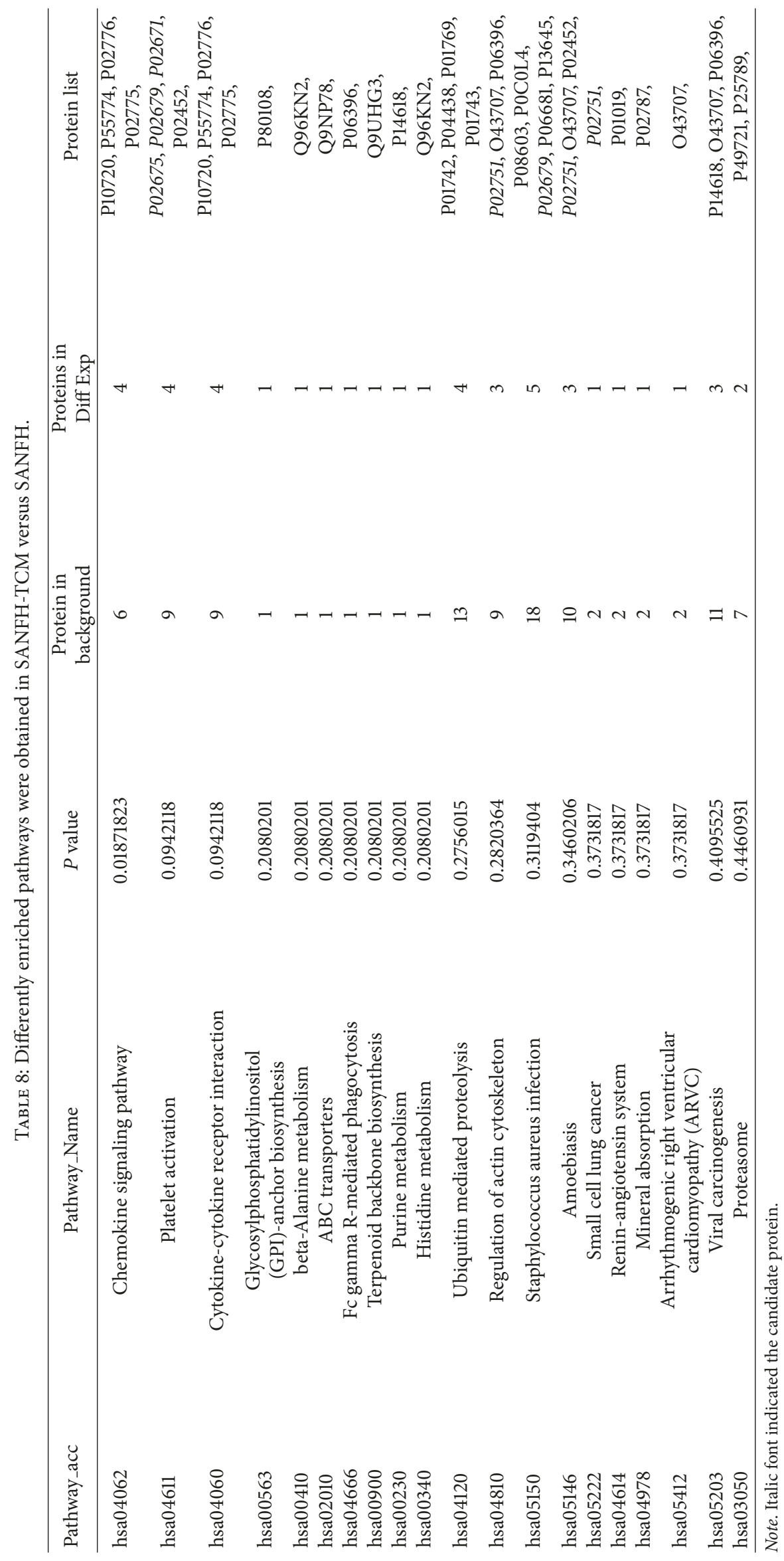


and 81 proteins between SANFH-TCM and SANFH. Those upregulated proteins including ABCB9, IQCA1, fibrinogen alpha, and fibrinogen beta and downregulated proteins including serum amyloid A-2 (SAA2), Ig lambda, CRP, and collagen alpha-1 are promising serum diagnosis markers of femoral head necrosis, and also the marker could be used for prognosis of femoral head necrosis after Traditional Chinese Medicine treatment. The key points of treating femoral head necrosis are early diagnosis, early treatment, and reserving femoral head of patients. Our findings on the screening of early serum diagnosis marker of femoral head necrosis are helpful for early intervention on patients with hormone risk factors and preventing femoral head necrosis.

\section{Conflicts of Interest}

The authors declare that they have no conflicts of interest.

\section{Acknowledgments}

The authors gratefully acknowledge the financial support of the grants from the National Natural Science Foundation of China (no. 81273784) and High-Level University Construction Project of Guangzhou University of Chinese Medicine (no. A1-AFD018171Z11068).

\section{References}

[1] C. Carulli, L. Nistri, L. Bracco, M. Giannini, and M. P. Amato, "A steroid-induced bilateral avascular necrosis of the femoral head in an underage patient affected by multiple sclerosis," Clinical Cases in Mineral and Bone Metabolism, vol. 12, no. 3, pp. 257259, 2015.

[2] A. F. Kamath, M. H. McGraw, and C. L. Israelite, "Surgical management of osteonecrosis of the femoral head in patients with sickle cell disease," World Journal of Orthopedics, vol. 6, no. 10, pp. 776-782, 2015.

[3] Y. Chen, C. Zeng, H. Zeng et al., "Comparative serum proteome expression of the steroid-induced femoral head osteonecrosis in adults," Experimental and Therapeutic Medicine, vol. 9, no. 1, pp. 77-83, 2015.

[4] A. Björkman, P. J. Svensson, A. Hillarp, I. M. Burtscher, A. Rünow, and G. Benoni, "Factor V Leiden and prothrombin gene mutation: risk factors for osteonecrosis of the femoral head in adults," Clinical Orthopaedics and Related Research, no. 425, pp. 168-172, 2004.

[5] S. Inoue, M. Horii, T. Asano et al., "Risk factors for nontraumatic osteonecrosis of the femoral head after renal transplantation," Journal of Orthopaedic Science, vol. 8, no. 6, pp. 751-756, 2003.

[6] H. Serre and L. Simon, "Primary osteonecrosis of the femur head in the adult. II. Etiology and pathogenesis," Rev Rhum Mal Osteoartic, vol. 29, pp. 536-545, 1962.

[7] C.-G. Li, L. Shen, Y.-P. Yang, X.-J. Xu, B. Shuai, and C. $\mathrm{Ma}$, "Effects of Modified Qinge Pill () on the expression of adiponectin, bone morphogenetic protein 2 and coagulationrelated factors in patients with nontraumatic osteonecrosis of the femoral head," Chinese Journal of Integrative Medicine, vol. 23, no. 3, pp. 183-189, 2017.

[8] M. A. Mont, J. J. Cherian, R. J. Sierra, L. C. Jones, and J. R. Lieberman, "Nontraumatic osteonecrosis of the femoral head: Where dowe stand today? A ten-year update," Journal of Bone and Joint Surgery - American Volume, vol. 97, no. 19, pp. 16041627, 2014.

[9] Z. Xu, X. Dai, Y. Yao et al., "Higher Levels of Serum Triglycerides Were Associated with Postoperative Deep Vein Thrombosis after Total Hip Arthroplasty in Patients with Nontraumatic Osteonecrosis of the Femoral Head," The International Journal of Lower Extremity Wounds, vol. 15, no. 1, pp. 41-44, 2016.

[10] J. Seamon, T. Keller, J. Saleh, and Q. Cui, "The pathogenesis of nontraumatic osteonecrosis," Arthritis \& Rheumatology, vol. 2012, Article ID 601763, 11 pages, 2012.

[11] A. Björkman, I. M. Burtscher, P. J. Svensson, A. Hillarp, J. Besjakov, and G. Benoni, "Factor V Leiden and the prothrombin 20210A gene mutation and osteonecrosis of the knee," Archives of Orthopaedic and Trauma Surgery, vol. 125, no. 1, pp. 51-55, 2005.

[12] I. R. Reid and J. Cornish, "Epidemiology and pathogenesis of osteonecrosis of the jaw," Nature Reviews Rheumatology, vol. 8, no. 2, pp. 90-96, 2012.

[13] K. Ikeuchi, Y. Hasegawa, T. Seki, Y. Takegami, T. Amano, and N. Ishiguro, "Epidemiology of nontraumatic osteonecrosis of the femoral head in Japan," Modern Rheumatology, vol. 25, no. 2, pp. 278-281, 2015.

[14] L. Wang, L. Zhang, H. Pan, S. Peng, X. Zhao, and W. W. Lu, "Abnormal subchondral bone microstructure following steroid administration is involved in the early pathogenesis of steroidinduced osteonecrosis," Osteoporosis International, vol. 27, no. 1, pp. 153-159, 2016.

[15] K. Tateda, S. Okazaki, S. Nagoya et al., "The suppression of TRIM21 and the accumulation of IFN- $\alpha$ play crucial roles in the pathogenesis of osteonecrosis of the femoral head," Laboratory Investigation, vol. 92, no. 9, pp. 1318-1329, 2012.

[16] D. Zhao, M. Yu, K. Hu et al., "Prevalence of nontraumatic osteonecrosis of the femoral head and its associated risk factors in the Chinese population: results from a nationally representative survey," Chinese Medical Journal, vol. 128, no. 21, pp. 2843-2850, 2015.

[17] J. Zeng, P. Deng, J. Li, W. Feng, J. Chen, and Y. Zeng, "Increased serum protein levels by Yuanshi Shengmai Chenggu Tablet in treatment of avascular osteonecrosis of the femoral head," Molecular Medicine Reports, 2017.

[18] A. Cave and P. Garlick, "Re: Preconditioning with ischemia: a delay of lethal cell injury in ischemic myocardium," Journal of Molecular and Cellular Cardiology, vol. 32, pp. 1759-1760, 2000.

[19] C. E. Murry, R. B. Jennings, and K. A. Reimer, "Preconditioning with ischemia: a delay of lethal cell injury in ischemic myocardium," Circulation, vol. 74, no. 5, pp. 1124-1136, 1986.

[20] Z.-Q. Zhao, J. S. Corvera, M. E. Halkos et al., "Inhibition of myocardial injury by ischemic postconditioning during reperfusion: comparison with ischemic preconditioning," American Journal of Physiology-Heart and Circulatory Physiology, vol. 285, pp. H579-H588, 2003.

[21] X. Tan, D. Cai, Y. Wu et al., "Comparative analysis of serum proteomes: discovery of proteins associated with osteonecrosis of the femoral head," Translational Research, vol. 148, no. 3, pp. 114-119, 2006.

[22] F. Shi, G. Li, H. Wang, and H. Yuan, "Antagonism of yuanshi shengmai chenggu capsule on steroid-induceds adipogenesis in rat marrow stromal cells," Journal of Guangzhou University of Traditional Chinese Medicine, vol. 20, pp. 302-304, 2003.

[23] J. Liu, Y. Fan, H. Wang et al., "Bone proteomic analysis about chinese medicine action on rat glucocorticoid - induced model 
of osteonecrsis," Chinese Journal of Traditional Medical Traumatology \& Orthopedics, vol. 13, pp. 5-9, 2005.

[24] A. Mangé, L. Dimitrakopoulos, A. Soosaipillai, P. Coopman, E. P. Diamandis, and J. Solassol, "An integrated cell linebased discovery strategy identified follistatin and kallikrein 6 as serum biomarker candidates of breast carcinoma," Journal of Proteomics, vol. 142, pp. 114-121, 2016.

[25] Y. Zhang, Y. Li, Y. Zhang et al., "Quantitative Proteomics Reveals Membrane Protein-Mediated Hypersaline Sensitivity and Adaptation in Halophilic Nocardiopsis xinjiangensis," Journal of Proteome Research, vol. 15, no. 1, pp. 68-85, 2016.

[26] R. Narumi and T. Tomonaga, "Quantitative analysis of tissue samples by combining itraq isobaric labeling with selected/ multiple reaction monitoring (SRM/MRM)," Methods in Molecular Biology, vol. 1355, pp. 85-101, 2016.

[27] C. Powell, C. Chang, and M. E. Gershwin, "Current concepts on the pathogenesis and natural history of steroid-induced osteonecrosis," Clinical Reviews in Allergy \&; Immunology, vol. 41, no. 1, pp. 102-113, 2011.

[28] Y. Assouline-Dayan, C. Chang, A. Greenspan, Y. Shoenfeld, and M. E. Gershwin, "Pathogenesis and natural history of osteonecrosis," Seminars in Arthritis and Rheumatism, vol. 32, no. 2, pp. 94-124, 2002.

[29] K. Kawai, A. Tamaki, and K. Hirohata, "Steroid-induced accumulation of lipid in the osteocytes of the rabbit femoral head," The Journal of Bone \& Joint Surgery, vol. 67, no. 5, pp. 755-763, 1985.

[30] W. Yin, Z. Xu, J. Sheng, C. Zhang, and Z. Zhu, "Logistic regression analysis of risk factors for femoral head osteonecrosis after healed intertrochanteric fractures," Hip International, vol. 26, no. 3, pp. 215-219, 2016.

[31] K. N. Malizos, A. H. Karantanas, S. E. Varitimidis, Z. H. Dailiana, K. Bargiotas, and T. Maris, "Osteonecrosis of the femoral head: etiology, imaging and treatment," European Journal of Radiology, vol. 63, no. 1, pp. 16-28, 2007.

[32] S. C. Li, C. Y. Lin, T. F. Kuo et al., "Chicken model of steroidinduced bone marrow adipogenesis using proteome analysis: A preliminary study," Proteome Science, vol. 8, article no. 47, 2010.

[33] R. W. Wu, F. S. Wang, J. Y. Ko, C. J. Wang, and S. Wu, "Comparative serum proteome expression of osteonecrosis of the femoral head in adults," Bone, vol. 43, no. 3, pp. 561-566, 2008.

[34] X.-Y. Wang, X.-H. Niu, W.-H. Chen et al., "Effects of apolipoprotein $\mathrm{A} 1$ and $\mathrm{B}$ gene polymorphism on avascular necrosis of the femoral head in Chinese population," Zhongguo gu shang = China journal of orthopaedics and traumatology, vol. 21, no. 2, pp. 99-102, 2008.

[35] B. Packialakshmi, R. Liyanage, J. O. Lay, R. Okimoto, and N. C. Rath, "Proteomic changes in the plasma of broiler chickens with femoral head necrosis," Biomarker Insights, vol. 11, pp. 5562, 2016.

[36] K. Miyanishi, T. Yamamoto, T. Irisa, Y. Noguchi, Y. Sugioka, and Y. Iwamoto, "Increased level of apolipoprotein B/apolipoprotein A1 ratio as a potential risk for osteonecrosis," Annals of the Rheumatic Diseases, vol. 58, no. 8, pp. 514-516, 1999.

[37] B. Packialakshmi, R. Liyanage, J. O. Lay, S. K. Makkar, and N. C. Rath, "Proteomic changes in chicken plasma induced by Salmonella typhimurium lipopolysaccharides," Proteomics Insights, vol. 7, no. 1, 2016.

[38] B. Shuai, L. Shen, Y. P. Yang, J. Xie, Z. X. Shou, and B. Wei, "Low plasma adiponectin as a potential biomarker for osteonecrosis of the femoral head," The Journal of Rheumatology, vol. 37, no. 10, pp. 2151-2155, 2010. 

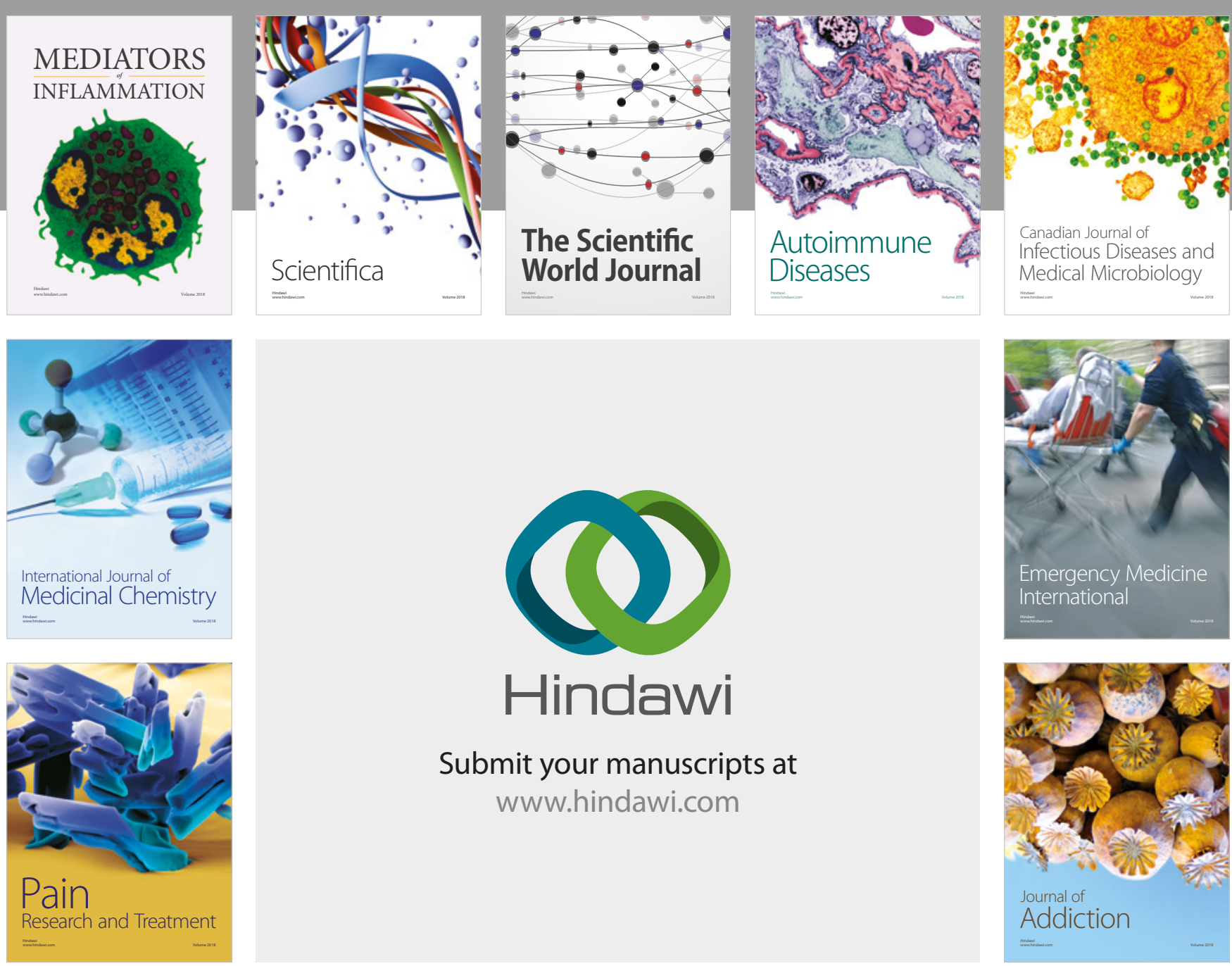

Canadian Journal of
Infectious Diseases and Medical Microbiology

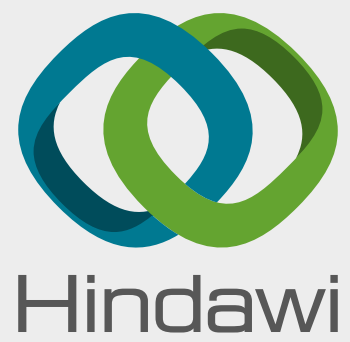

Submit your manuscripts at

www.hindawi.com
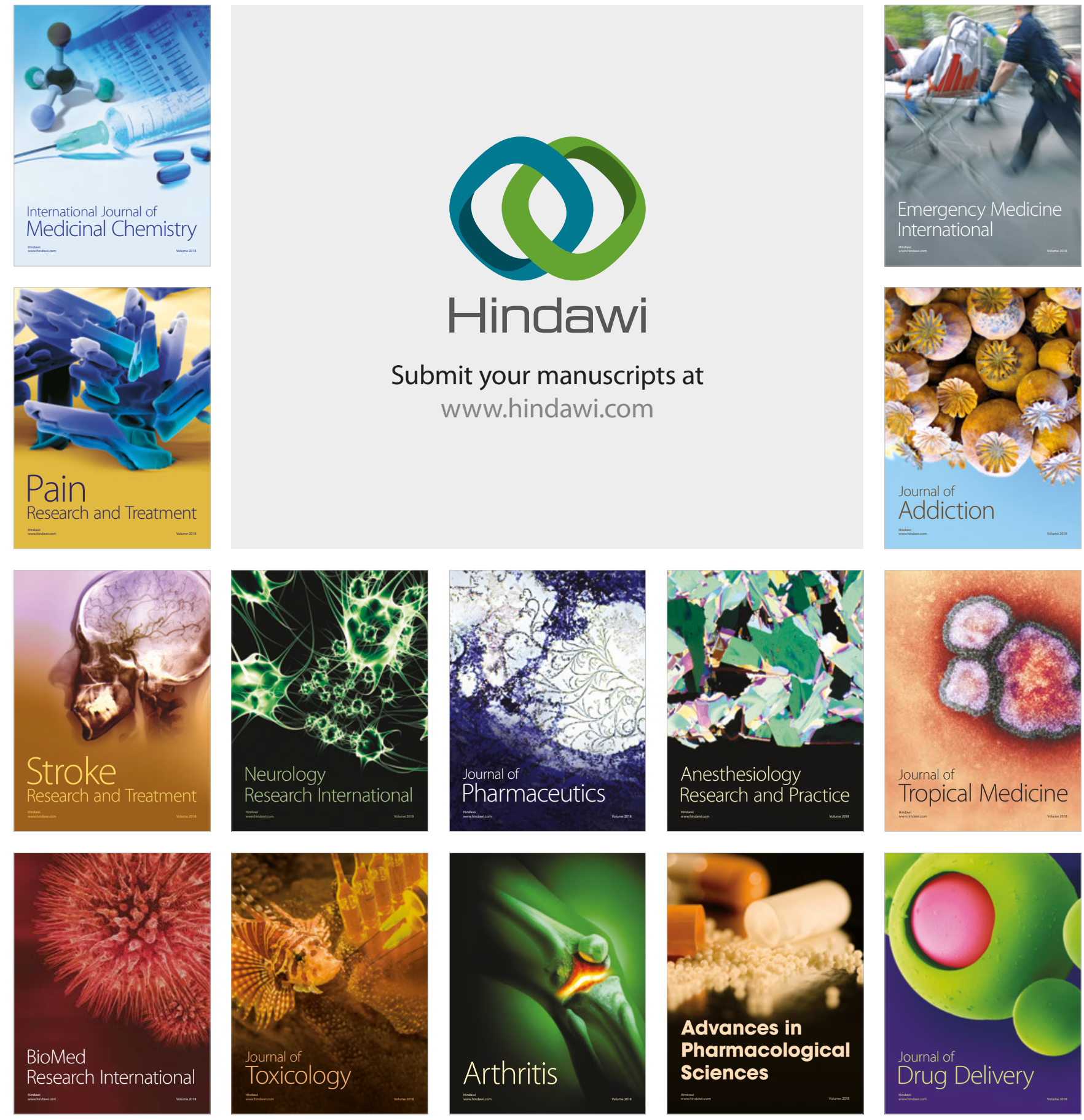